\title{
SOEP
}

SOEPpapers

SOEPpapers
on Multidisciplinary Panel Data Research
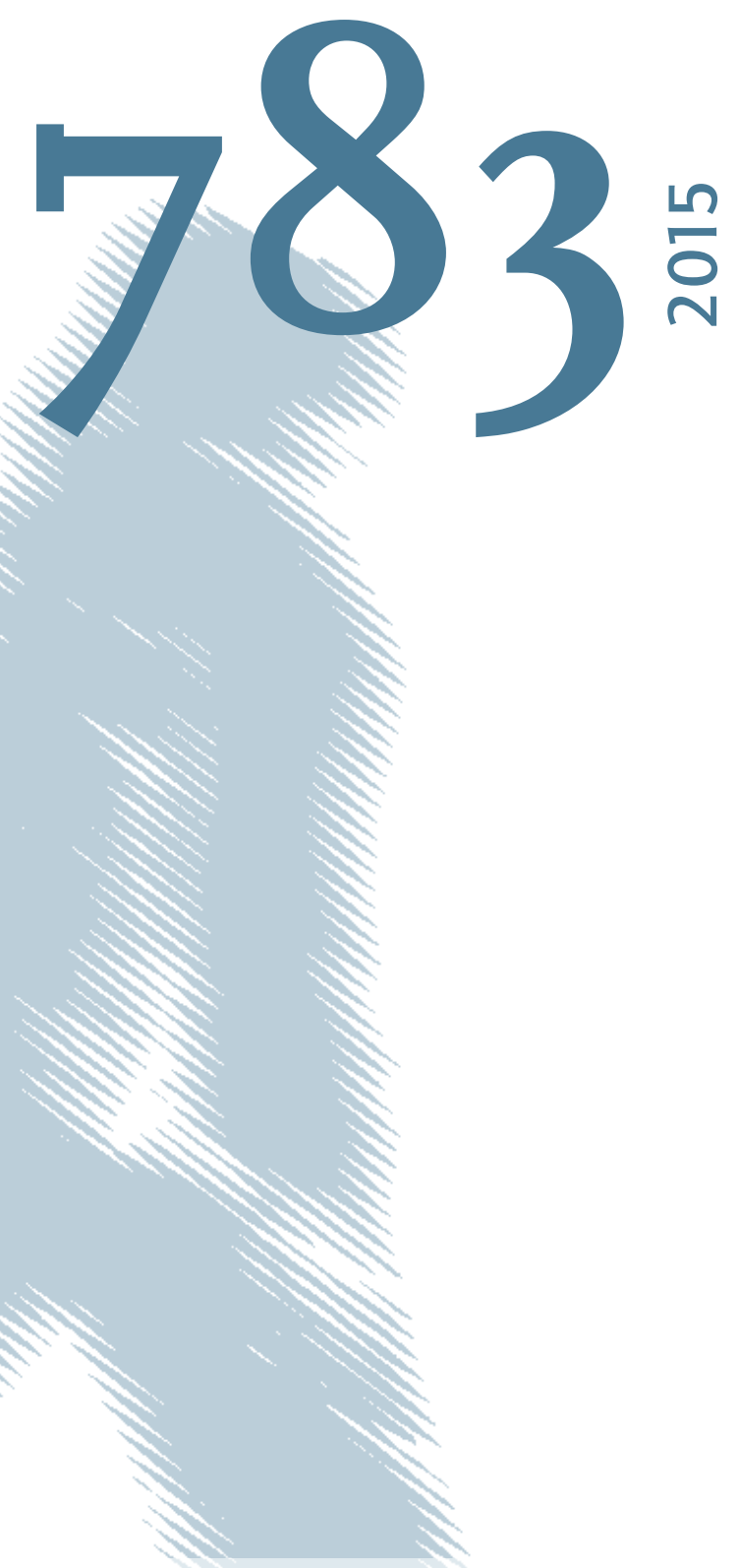

\section{Personality and smoking: individual- participant meta-analysis of 9 cohort studies}

Christian Hakulinen, Mirka Hintsanen, Marcus R. Munafò, Marianna Virtanen, Mika Kivimäki, G. David Batty, Markus Jokela 
This series presents research findings based either directly on data from the German SocioEconomic Panel study (SOEP) or using SOEP data as part of an internationally comparable data set (e.g. CNEF, ECHP, LIS, LWS, CHER/PACO). SOEP is a truly multidisciplinary household panel study covering a wide range of social and behavioral sciences: economics, sociology, psychology, survey methodology, econometrics and applied statistics, educational science, political science, public health, behavioral genetics, demography, geography, and sport science.

The decision to publish a submission in SOEPpapers is made by a board of editors chosen by the DIW Berlin to represent the wide range of disciplines covered by SOEP. There is no external referee process and papers are either accepted or rejected without revision. Papers appear in this series as works in progress and may also appear elsewhere. They often represent preliminary studies and are circulated to encourage discussion. Citation of such a paper should account for its provisional character. A revised version may be requested from the author directly.

Any opinions expressed in this series are those of the author(s) and not those of DIW Berlin. Research disseminated by DIW Berlin may include views on public policy issues, but the institute itself takes no institutional policy positions.

The SOEPpapers are available at http://www.diw.de/soeppapers

\section{Editors:}

Jan Goebel (Spatial Economics)

Martin Kroh (Political Science, Survey Methodology)

Carsten Schröder (Public Economics)

Jürgen Schupp (Sociology)

Conchita D'Ambrosio (Public Economics)

Denis Gerstorf (Psychology, DIW Research Director)

Elke Holst (Gender Studies, DIW Research Director)

Frauke Kreuter (Survey Methodology, DIW Research Fellow)

Frieder R. Lang (Psychology, DIW Research Fellow)

Jörg-Peter Schräpler (Survey Methodology, DIW Research Fellow)

Thomas Siedler (Empirical Economics)

C. Katharina Spieß (Education and Family Economics)

Gert G. Wagner (Social Sciences)

ISSN: 1864-6689 (online)

German Socio-Economic Panel Study (SOEP)

DIW Berlin

Mohrenstrasse 58

10117 Berlin, Germany

Contact: Uta Rahmann | soeppapers@diw.de 


\title{
Personality and smoking: individual-participant meta-analysis of 9 cohort studies
}

\author{
Christian Hakulinen
}

Institute of Behavioural Sciences, University of Helsinki, Finland

Mirka Hintsanen

Institute of Behavioural Sciences, University of Helsinki, Finland

Unit of Psychology, Faculty of Education, University of Oulu, Finland

Marcus R. Munafò

MRC Integrative Epidemiology Unit, UK Centre for Tobacco and Alcohol Studies, and

School of Experimental Psychology, University of Bristol, UK

Marianna Virtanen

Finnish Institute of Occupational Health, Finland

Mika Kivimäki

Department of Epidemiology and Public Health, University College London, UK

Department of Public Health, Faculty of Medicine, University of Helsinki, Finland.

G. David Batty

Department of Epidemiology and Public Health, University College London, UK

Centre for Cognitive Ageing and Cognitive Epidemiology, University of Edinburgh, UK

Alzheimer Scotland Dementia Research Centre, University of Edinburgh, UK

Markus Jokela

Institute of Behavioural Sciences, University of Helsinki, Finland

Corresponding author: Christian Hakulinen, Institute of Behavioural Sciences, P.O. Box 9, 00014 University of Helsinki, Finland. Telephone: +358 50448 2041, E-mail:

christian.hakulinen@helsinki.fi

Running head: Personality and smoking

Manuscript statistics: 3310 words; 1 table; 2 figures; online supplement (6 tables and 5

figures)

Disclosure: The authors state no conflicts of interest.

This article has been accepted for publication in 'Addiction' at Wiley and undergone full peer review but has not been through the copyediting, typesetting, pagination and proofreading process which may lead to differences between this version and the Version of Record. Please cite this article as doi: 10.1111/add.13079 
Aims: To investigate cross-sectional and longitudinal associations between personality and smoking, and test whether sociodemographic factors modify these associations.

Design: Cross-sectional and longitudinal individual-participant meta-analysis.

Setting: Nine cohort studies from Australia, Germany, UK and US.

Participants: A total of 79,757 men and women (mean age $=51$ years).

Measurements: Personality traits of the Five-Factor Model (extraversion, neuroticism, agreeableness, conscientiousness and openness to experience) were used as exposures. Outcomes were current smoking status (current smoker, ex-smoker, and never smoker), smoking initiation, smoking relapse, and smoking cessation. Associations between personality and smoking were modeled using logistic and multinomial logistic regression, and study-specific findings were combined using random-effect meta-analysis.

Findings: Current smoking was associated with higher extraversion (odds ratio per 1 standard deviation increase in the score: 1.16 ; $95 \%$ confidence interval: $1.08-1.24)$, higher neuroticism (1.19; 1.13-1.26), and lower conscientiousness (0.88; 0.83-0.94). Among nonsmokers, smoking initiation during the follow-up period was prospectively predicted by higher extraversion $(1.22 ; 1.04-1.43)$ and lower conscientiousness $(0.80 ; 0.68-0.93)$, whereas higher neuroticism $(1.16 ; 1.04-1.30)$ predicted smoking relapse among ex-smokers. Among smokers, smoking cessation was negatively associated with neuroticism $(0.91 ; 0.87-0.96)$. Sociodemographic variables did not appear to modify the associations between personality and smoking.

Conclusions: Adult smokers have higher extraversion, higher neuroticism and lower conscientiousness personality scores than non-smokers. Initiation into smoking is positively associated with higher extraversion and lower conscientiousness, while relapse to smoking among ex-smokers is association with higher neuroticism. 
Despite the known harmful effects of smoking on health (1), around $31 \%$ of men and $11 \%$ of women worldwide continue to smoke tobacco regularly (2). In the United States, $67 \%$ of regular smokers have considered quitting smoking, and $52 \%$ had attempted to do so during the past year (3). While there are many effective smoking cessation programs, such as behavioral support and pharmacological treatments (4), people's attempts to quit smoking tend not to be successful over the long term $(3,5)$.

Several psychological and social risk factors for smoking have been identified, including parental socioeconomic status, parental smoking, and peer smoking (6). Previous research has also reported differences in personality characteristics - which refers to individual differences in feelings, thoughts, and actions (7) - between smokers and non-smokers $(8,9)$. A metaanalysis of 25 published cross-sectional studies of extraversion and neuroticism (34,738 nonsmokers and 12,764 smokers) reported that smokers had higher neuroticism and higher extraversion than non-smokers (10). Another meta-analysis of published cross-sectional studies on health correlates of conscientiousness $(n=46,725)$ reported that smoking was more common among individuals with low compared with high conscientiousness (11). In addition, a cross-sectional association between low agreeableness and current smoking was reported in a meta-analysis that was based on nine published studies $(n=4,730)(12)$. In sum, current smokers are characterized by high neuroticism, high extraversion, low agreeableness, and low conscientiousness.

The role of personality in future smoking behaviors has also been examined. In prospective studies, high neuroticism has been shown to be associated with smoking initiation in some (13-15), but not in all studies (16). Low conscientiousness has been shown to be associated with smoking initiation $(13,16)$, while the evidence of the association between high openness to experience and smoking initiation is mixed with both positive and null findings $(13,16)$. Results from two small-scale smoking cessation programs suggests 
that low neuroticism and low openness to experience may be associated with higher odds of smoking cessation $(17,18)$, and that higher conscientiousness might predict abstinence from smoking (17).

In sum, the majority of studies on smoking and personality have been cross-sectional and have focused only on some of the personality traits of the five-factor model instead of examining them all together. Even fewer longitudinal studies have assessed all the major dimensions of personality in relation to different smoking behaviors, including smoking initiation, relapse, and cessation. These studies have been carried out with relatively small samples. Thus, large-scale studies are needed to establish robustness of the associations between personality and smoking behaviors. Furthermore, it remains unclear whether sociodemographic factors might modify the association between personality and smoking behavior. For example, while some studies suggest that the association between personality and smoking is stronger among women than men (16), other studies report no gender differences $(13,14)$. The association between conscientiousness and smoking has been reported to be weaker among older compared with younger age groups (11), but this finding has not been replicated. Education has been linked to smoking behaviors (19), and it has been suggested that there is an interaction between education and personality on smoking (20). In addition, the association of psychological distress (a concept closely related to high neuroticism) with smoking has been suggested to differ between ethnic groups (21). However, further research is needed to clarify whether these sociodemographic characteristics are of importance in the relation between personality and smoking. Most previous studies have also not examined subgroup differences with regard to other smoking behaviors besides current smoking.

The aim of the present study was to examine associations between personality traits of the five-factor model (extraversion, neuroticism, agreeableness, conscientiousness, and 
openness to experience) and smoking behavior in cross-sectional and longitudinal settings. More specifically, we examined whether personality traits predict smoking initiation, smoking relapse, and smoking cessation, and whether sociodemographic factors modify these associations. To achieve all this, we pooled data from nine large cohort studies for an individual-participant meta-analysis of 79,757 participants. Individual-participant metaanalysis is seen as the gold standard approach to evidence synthesis and it is an effective way to reduce the potential problem of publication bias (22), from which the previous metaanalyses based on publish studies might suffer. Based on previous research we hypothesized that higher extraversion and neuroticism, and lower agreeableness and conscientiousness, would be related to higher probability of smoking and smoking initiation, smoking relapse, and with lower probability of smoking cessation.

\section{Methods and Materials}

Data were selected by searching the data collections of the Inter-University Consortium for Political and Social Research (ICPSR; http://www.icpsr.umich.edu/icpsrweb/ICPSR/) and the Economic and Social Data Service (http://ukdataservice.ac.uk/) to identify eligible large-scale cohort studies that have measurements of personality and smoking. To be eligible for inclusion, studies needed to be open access datasets, have a sufficiently large sample size $(n>1000)$, had to include information on participant's smoking status, and personality assessed with at least the brief 15-item questionnaire or with more comprehensive questionnaires based on the Five-Factor Model of personality.

The following cohort studies met the inclusion criteria: the National Longitudinal Study of Adolescent Health (Add Health), the British Household Panel Survey (BHPS), the German Socio-Economic Panel Study (GSOEP), the Household, Income and Labour Dynamics in Australia (HILDA) Survey, the Health and Retirement Study (HRS), the Midlife in the 
United States (MIDUS), the National Child Development Study (NCDS) the Wisconsin Longitudinal Study graduate (WLSG) sample, and the Wisconsin Longitudinal Study sibling (WLSS) sample. All these studies are well-characterized longitudinal cohort studies with large sample sizes. However, Add Health and NCDS did not have follow-up data on smoking after the assessment of personality, and thus these cohort studies were included only in crosssectional analyses. All the cohort studies have been approved by the relevant local ethics committees. Full details of the cohort studies and used measures are provided in the Online Supplementary Appendix.

\section{Measures}

The Five-Factor Model personality traits were assessed with standardized questionnaire instruments. These instruments measure the following five higher-order personality traits that sum up individual variation in several, more precise, personality dispositions: extraversion (e.g., sociability and sensitivity to positive emotions), neuroticism (e.g., low emotional stability and proneness to anxiety), agreeableness (e.g., cooperativeness and trust toward other people), conscientiousness (e.g., self-control and allegiance to social norms), and openness to experience (e.g., curiosity and open-mindedness) (23).

Current smoking at baseline was measured with different questions across cohort studies that were categorized as follows: $0=$ never-smoker; $1=$ ex-smoker; $2=$ current smoker. At the follow-up, the same procedure was followed, except that current smoking was categorized as follows: $0=$ non-smoker; $1=$ current smoker. Sociodemographics were harmonized across cohort studies as follows: marital status ( $0=$ single, $1=$ married/cohabiting), race/ethnicity $(0=$ white, non-Hispanic; $1=$ other $)$, and educational level $(0=$ primary education, $1=$ secondary education, $2=$ tertiary education). 


\section{Statistical analysis}

Cross-sectional associations between personality traits and current smoking in the total sample and within different subgroups were examined using multinomial logistic regression $(0=$ never-smoker; 1 =ex-smoker; 2 = current smoker $)$, where never-smokers were used as a comparison group. Odds ratios (ORs) were calculated for personality z-scores (Standard Deviation $[\mathrm{SD}]=1$ ). Longitudinal associations between personality traits and smoking were analyzed in three separate analyses. First, the association between personality traits and smoking initiation among never-smokers was examined. Second, the association between personality traits smoking relapse among ex-smokers was investigated. Third, the association between personality traits and smoking cessation among baseline smokers was examined. All models were adjusted for sex, age at baseline, and ethnicity/nationality. Longitudinal analyses were further adjusted for follow-up period in months.

To examine whether the association between personality traits and smoking behaviors differed between sociodemographic groups, we carried out stratified analyses by sex (men vs women), age groups (under 40 years, between 40 to 65 years, or over 65 years), marital status (single vs married/cohabiting), race/ethnicity (white vs other), and educational level (primary, secondary, or tertiary education). The study-specific results were then pooled together by subgroup using meta-analysis and then heterogeneity across subgroups was examined using the $\mathrm{I}^{2}$ statistic. In addition to these subgroup analyses, longitudinal analyses were conducted separately according to the length of follow-up (i.e., short (4 years or less on average) vs long (4 years or more on average)) to examine whether the follow-up time would moderate the association between personality and smoking behaviors.

Meta-analysis was performed using the two-step approach, all models were first fitted separately within each cohort studies and the results from the individual cohort studies were then pooled together by using random-effects meta-analysis. Heterogeneity in the effect sizes 
was examined using the $\mathrm{I}^{2}$ estimates. Additional sensitivity analyses were performed to examine whether covariates and their interactions with personality traits explained heterogeneity. Sensitivity analyses were done by first pooling all data together, and then using one-step individual-participant meta-analysis (i.e., logistic multilevel mixed-effects regression analysis). Meta-analysis was performed with the metan package of Stata, version 13.1, software (StataCorp LP, College Station, Texas) and the sensitivity analyses were performed using R package lme4 (24).

\section{Results}

The total sample included 79,757 participants (age range 15-104, mean age 50.8 years) and 52,684 participants were included in the longitudinal analysis (follow-up mean: 5.2 years; follow-up range: from 15 months to 157 months). Characteristics of the samples are presented in Table $\mathbf{1 .}$

\section{Current-smoking status}

Cross-sectional analyses, where the association between personality and current smoking status was examined, are presented in Figure 1. Higher extraversion (pooled OR 1.16; 95\% CI 1.08-1.24) and higher neuroticism (OR 1.19; 95\% CI 1.13-1.26) were associated with an increased risk of smoking. These associations were, however, not consistent across studies $\left(\mathrm{I}^{2}=90 \%\right.$ for extraversion; $\mathrm{I}^{2}=87 \%$ for neuroticism), suggesting high heterogeneity between studies (Supplement Figure 1). In addition, lower conscientiousness was associated with lower likelihood of smoking (pooled OR $0.88 ; 95 \%$ CI $0.83-0.94$ ), which was also not consistent across individual studies $\left(\mathrm{I}^{2}=90 \%\right)$.

Similar results were found when ex-smokers where compared with never-smokers; higher extraversion (pooled OR 1.13; 95\% CI 1.08-1.17), higher neuroticism (OR 1.13; 95\% 
CI 1.07-1.19), and lower conscientiousness (pooled OR 0.93; 95\% CI 0.90-0.97) were associated with an increased likelihood of being an ex-smoker. In addition, lower agreeableness (pooled OR 0.90; 95\% CI 0.85-0.94) and higher openness to experience (OR 1.07; 95\% CI 1.04-1.12) were also associated with an increased likelihood of being an exsmoker. However, $\mathrm{I}^{2}$ values suggested that there was high heterogeneity in the associations across studies ( $\mathrm{I}^{2}$ values between $72 \%$ and $90 \%$; for study specific associations see

Supplement Figure 2). Although individual studies suggested some statistically significant cross-sectional associations for agreeableness and openness to experience, the meta-analysis suggested no pooled associations for these two traits.

\section{Smoking initiation, relapse, and cessation}

Figure 2 presents the associations of the personality traits with (1) smoking initiation among baseline non-smokers, (2) smoking relapse among baseline ex-smokers, and (3) smoking cessation among baseline smokers. Higher extraversion (pooled OR 1.22; 95\% CI 1.04-1.43) and lower conscientiousness (pooled OR $0.80 ; 95 \%$ CI 0.68-0.93) were consistently associated with higher odds of smoking initiation (Supplement Figure 3). Higher neuroticism (pooled OR 1.16; 95\% CI 1.04-1.30) was associated with higher odds of smoking relapse among ex-smokers (Supplement Figure 4). Higher neuroticism was consistently associated with lower odds of smoking cessation among those who smoked at baseline (pooled OR 0.91; 95\% CI 0.87-0.96) (Supplement Figure 5).

\section{Sub-group and sensitivity analyses}

Cross-sectional sub-group analyses between personality traits and current smoking status are presented in Supplemental Table 1 and 2. No significant sources of heterogeneity, which would explain the large heterogeneity found in the main analysis, were found in sub-group 
analyses. However, the associations between extraversion and neuroticism with smoking at baseline did not remain statistically significant among participants older than 65 years (OR 1.02; 95\% CI 0.87-1.17; OR 1.07; 95\% CI 0.93-1.21; respectively).

Longitudinal sub-group analyses between personality traits and smoking initiation, smoking relapse, and smoking cessation are presented in Supplemental Tables 3-5, respectively. The earlier sub-group findings between personality traits and smoking at baseline were not replicated in the longitudinal sub-group analyses. However, high extraversion predicted smoking relapse only among studies with long follow-up (OR 1.20; 95\% CI 1.01-1.42), whereas high agreeableness predicted smoking relapse among studies with short-follow-up (OR 1.17; 95\% CI 1.05-1.31).

Additional sensitivity analyses suggested that results from the two-step and one-step individual participant meta-analysis were similar (Supplemental Table 6). Observed heterogeneity between studies in the association between neuroticism and relapse was reduced $94 \%$ when moderators and interactions between personality traits and moderators were included in the one-step multilevel logistic regression model.

\section{Discussion}

In an individual-participant meta-analysis of nine cohort studies higher neuroticism, higher extraversion, and lower conscientiousness were associated with increased probability of smoking. However, whereas higher extraversion and lower conscientiousness were associated with smoking initiation, only high neuroticism was associated with smoking relapse, indicating that personality is differently associated with smoking initiation and relapse. Among those smoking at baseline, smoking cessation was predicted by lower neuroticism but not by extraversion or conscientiousness. 
Many of the present results are in agreement with previously published data. In a metaanalysis of 25 published cross-sectional studies (total $n>47,000$ ) investigating extraversion and neuroticism, smoking was associated with higher neuroticism and higher extraversion (10) The effect size for extraversion was larger in the previously published meta-analysis (OR 1.41; 95\% CI 1.29-1.57; transformed from Cohen's d=0.19; 95\% CI 0.14 to 0.25 ) compared with our current study (pooled OR 1.16; 95\% CI 1.08-1.24). Similarly, the effect size for neuroticism was slightly larger (OR 1.24; 95\% CI 1.08-1.44; transformed from Cohen's d $=0.12 ; 95 \%$ CI 0.04 to 0.20 ) than that observed in our present study (pooled OR 1.19; $95 \%$ CI 1.13-1.26). In another meta-analysis of published studies examining health correlates of conscientiousness, $(n=47,000)$, higher conscientiousness was associated with lower likelihood of smoking (11). Again, the effect size was considerably larger in this metaanalysis (OR 0.60; 95\% CI 0.58-0.62; transformed from a correlation based effect size $\mathrm{r}=-$ 0.14 ; $95 \%$ CI -0.13 to -0.15) compared with our current study (pooled OR 0.88 ; 95\% CI 0.830.94). However, whereas a previous meta-analysis with 4,730 participants found an association between low agreeableness and current smoking, this association was not found in the current study (12). In addition, contrary to prior longitudinal evidence (13-16), neuroticism and openness to experience were not associated with smoking initiation.

The effect sizes tended to be lower in our analyses than in the two previous metaanalyses $(10,11)$. For example, the effect estimate for the association between conscientiousness and smoking was $32 \%$ lower in our study compared with the earlier metaanalysis based on published studies (11). Several reasons might explain why our results differed in terms of magnitude from those in previous meta-analyses $(10,11)$. First, metaanalyses based on published data can be affected by publication bias, which is caused by selective publishing of positive findings, and can artificially inflate effect estimates (25). In the current study, data were obtained from two public databases and the analyses were 
preplanned, thus the final results were not influenced by the results from individual cohort studies. This procedure is likely to reduce the problem of selectively publishing significant findings only. Indeed, similar differences between published and unpublished studies have been also found in previous IPD meta-analyses of psychosocial factors and health (26), including the association between personality and all-cause mortality (27).

Our analyses indicated that there was heterogeneity in the results between the cohort studies. Some heterogeneity can be naturally expected as included cohort studies were from different countries and used different sampling methods. However, our sensitivity analyses suggested that observed between-study heterogeneity in neuroticism-smoking relapse association was substantially reduced when moderators and interactions between personality traits and moderators were included in the sensitivity analyses. Thus, it is likely that the subgroup differences are of importance in individual cohort studies, but they are not so consistent that they would be seen at the meta-analytic level. However, it is also likely there are, for example, some socio-cultural and biological factors, which we were not able to measure, that could explain the observed heterogeneity across studies. Further research is needed to identify these factors.

Different psychological processes may underlie smoking initiation, smoking relapse, and smoking cessation (28-30). Our findings show that personality is also differentially associated with some of these smoking behaviors; higher extraversion and lower conscientiousness were associated with smoking initiation, whereas lower neuroticism was associated with smoking cessation and higher neuroticism was associated with smoking relapse. These findings are plausible. High extraversion is related to sensation seeking and sociability, and as smoking is often a social activity, individuals with higher extraversion might start smoking and smoke more just because they are more social. High neuroticism, in turn, reflects low emotional stability and high proneness to anxiety and stress. Given that smoking may represent a 
strategy to relieve stress (31), the stress-proneness and higher levels of negative emotions among neurotic individuals may explain their higher odds of smoking relapse. We also found that high neuroticism was associated with a lower likelihood of smoking cessation. This may also be related to their stress-proneness. Furthermore, smoking cessation introduces withdrawal symptoms, and these symptoms may be experienced more strongly by individuals with high neuroticism.

Previous individual-participant meta-analyses have identified conscientiousness as the central health related personality trait. Low conscientiousness has been found to predict obesity (32), diabetes (33), cardiovascular disease and stroke (34) and all-cause mortality (27), and many unfavorable health behaviors $(11,35)$. Cancer appears to be one of the few health outcomes that is not predicted by low conscientiousness - or by any other personality trait (36). High conscientiousness reflects good self-control and capacity for long-term planning, so the lower smoking behavior associated with conscientiousness is likely to reflect the greater adherence to healthy lifestyle and public health recommendations.

There have been repeated calls to include personality information in health behavior interventions $(37,38)$. Our results suggest that although the magnitude of the personalitysmoking relationship might be smaller than previously reported, personality is clearly associated with smoking behavior. In particular, increased attention and support to individuals high on the personality dimension neuroticism could improve the outcome of smoking cessation interventions. A recent study suggests that interventions targeted to adolescents who display high anxiety sensitivity and hopelessness (i.e., high neuroticism) may be effective in preventing and reducing problematic drinking (39). Our findings imply that this could also be the case in interventions promoting smoking cessation. In addition, as neuroticism is related to depressive symptoms $(40,41)$ and depression is highly co-morbid with smoking (42), personality-informed interventions to reduce smoking could also support 
those with depressive symptoms. Further research should also investigate whether the success in current smoking cessations programs vary depending on individuals personality dispositions.

Some methodological limitations need to be acknowledged. Smoking status was selfreported, which might lead to the underestimation of smoking prevalence (43). It is possible, for example, that individuals classified as ex-smokers were smokers relatively long-time ago, or that current smokers respond as being ex-smokers due to social desirability. The study cohort included mainly middle-aged Caucasian participants and thus results might not be generalizable to other ethnical groups. Current study also contained relatively few initiators, which might bias the results. Although, the Five-Factor model is one of the most used conceptualization of personality structure, and it has considerable empirical support (7), it has also been criticized; its structure and usefulness at the individual level has been questioned (44) and it has also been seen too broad to capture all the possible variation in personality traits (45). Personality was measured with different instruments of the five-factor traits in different cohort studies, which could have introduced heterogeneity in the associations. However, different instruments of the five-factor traits have been shown to correlate strongly with each other, suggesting that this may not have been a major source of heterogeneity in the current meta-analysis $(7,46)$.

In conclusion, this individual-participant meta-analysis showed that high extraversion, high neuroticism and low conscientiousness are associated with smoking behavior, although the effect sizes were lower than those reported in previous meta-analyses, which were based on published data. Smoking cessation was predicted only by low neuroticism, suggesting that behavioral, emotional and cognitive dispositions related to this personality dimension may be particularly relevant for interventions. 


\section{Acknowledgements:}

M.R.M. is a member of the United Kingdom Centre for Tobacco and Alcohol Studies, a UKCRC Public Health Research: Centre of Excellence. Funding from British Heart Foundation, Cancer Research UK, Economic and Social Research Council, Medical Research Council, and the National Institute for Health Research, under the auspices of the UK Clinical Research Collaboration, is gratefully acknowledged. M.V. is supported by the Academy of Finland $(258598,265174)$. M.K. is supported by the UK Medical Research Council (K013351), the Economic and Social Research Council, the Academy of Finland, and the US National Institutes of Health (R01HL036310, R01AG034454). G.D.B. is a member of the Alzheimer Scotland Dementia Research Centre funded by Alzheimer Scotland, and the University of Edinburgh Centre for Cognitive Ageing and Cognitive Epidemiology, part of the cross council Lifelong Health and Wellbeing Initiative (G0700704/ 84698). Funding from the BBSRC, EPSRC, ESRC, and MRC is gratefully acknowledged. 


\section{References}

1. Lim S.S., Vos T., Flaxman A.D., Danaei G., Shibuya K., Adair-Rohani H., et al. A comparative risk assessment of burden of disease and injury attributable to 67 risk factors and risk factor clusters in 21 regions, 1990-2010: a systematic analysis for the Global Burden of Disease Study 2010. The lancet 2013; 380: 2224-60.

2. Ng M., Freeman M.K., Fleming T.D., Robinson M., Dwyer-Lindgren L., Thomson B., et al. Smoking prevalence and cigarette consumption in 187 countries, 1980-2012. JAMA 2014; 311: 183-92.

3. Centers for Disease Control and Prevention. Quitting smoking among adults—United States, 2001-2010. Morbidity and Mortality Weekly Report 2011; 60: 1513-9.

4. Hartmann- Boyce J., Stead L.F., Cahill K., Lancaster T. Efficacy of interventions to combat tobacco addiction: Cochrane update of 2012 reviews. Addiction 2013; 108: 1711-21.

5. Kotz D., West R. Explaining the social gradient in smoking cessation: it's not in the trying, but in the succeeding. Tob Control 2009; 18: 43-6.

6. Tyas S.L., Pederson L.L. Psychosocial factors related to adolescent smoking: a critical review of the literature. Tob Control 1998; 7: 409-20.

7. John O.P., Naumann L.P., Soto C.J. Paradigm shift to the integrative big-five trait taxonomy: History, measurement, and conceptual issues. In: John O.P., Robins R.W., Pervin L.A., editors. Handbook of Personality: Theory and Research. New York: Guilford Press; 2008. p. 114-58. 
8. Cherry N., Kiernan K. Personality scores and smoking behaviour. A longitudinal study. $\mathrm{Br}$ J Prev Soc Med 1976; 30: 123-31.

9. Terracciano A., Costa P.T. Smoking and the Five- Factor Model of personality. Addiction 2004; 99: 472-81.

10. Munafo M.R., Zetteler J.I., Clark T.G. Personality and smoking status: A meta-analysis. Nicotine Tobacco Res 2007; 9: 405-13.

11. Bogg T., Roberts B.W. Conscientiousness and health-related behaviors: a meta-analysis of the leading behavioral contributors to mortality. Psychol Bull 2004; 130: 887-919.

12. Malouff J.M., Thorsteinsson E.B., Schutte N.S. The five-factor model of personality and smoking: A meta-analysis. J Drug Educ 2006; 36: 47-58.

13. Turiano N.A., Whiteman S.D., Hampson S.E., Roberts B.W., Mroczek D.K. Personality and substance use in midlife: Conscientiousness as a moderator and the effects of trait change. Journal of research in personality 2012; 46: 295-305.

14. Welch D., Poulton R. Personality influences on change in smoking behavior. Health Psychology 2009; 28: 292-9.

15. Munafo M.R., Black S. Personality and smoking status: a longitudinal analysis. Nicotine Tob Res 2007; 9: 397-404.

16. Hampson S.E., Goldberg L.R., Vogt T.M., Dubanoski J.P. Forty years on: teachers' assessments of children's personality traits predict self-reported health behaviors and outcomes at midlife. Health psychology 2006; 25: 57-64. 
17. del Río E.F., López-Durán A., Rodríguez-Cano R., Martínez Ú, Martínez-Vispo C., Becoña E. Facets of the NEO-PI-R and smoking cessation. Personality and Individual Differences 2015; 80: 41-5.

18. Hooten W.M., Wolter T.D., Ames S.C., Hurt R.D., Vickers K.S., Offord K.P., et al. Personality correlates related to tobacco abstinence following treatment. The International Journal of Psychiatry in Medicine 2005; 35: 59-74.

19. Hiscock R., Bauld L., Amos A., Fidler J.A., Munafò M. Socioeconomic status and smoking: a review. Ann N Y Acad Sci 2012; 1248: 107-23.

20. Chapman B., Fiscella K., Duberstein P., Kawachi I. Education and smoking: confounding or effect modification by phenotypic personality traits? Annals of Behavioral Medicine 2009; 38: $237-48$.

21. Kiviniemi M.T., Orom H., Giovino G.A. Psychological distress and smoking behavior: the nature of the relation differs by race/ethnicity. Nicotine Tob Res 2011; 13: 113-9.

22. Riley R.D., Lambert P.C., Abo-Zaid G. Meta-analysis of individual participant data: rationale, conduct, and reporting. BMJ: British Medical Journal 2010: 521-5.

23. Digman J.M. Personality structure: Emergence of the five-factor model. Annu Rev Psychol 1990; 41: 417-40.

24. Bates D., Maechler M., Bolker B., Walker S., Christensen R.H.B., Singmann H., et al. Package 'Ime4'. R Foundation for Statistical Computing, Vienna 2014.

25. Rosenthal R. The file drawer problem and tolerance for null results. Psychol Bull 1979; 86: 638-641. 
26. Kivimäki M., Nyberg S.T., Batty G.D., Fransson E.I., Heikkilä K., Alfredsson L., et al. Job strain as a risk factor for coronary heart disease: a collaborative meta-analysis of individual participant data. The Lancet 2012; 380: 1491-7.

27. Jokela M., Batty G.D., Nyberg S.T., Virtanen M., Nabi H., Singh-Manoux A., et al. Personality and All-Cause Mortality: Individual-Participant Meta-Analysis of 3,947 Deaths in 76,150 Adults. American Journal of Epidemiology 2013; 178: 667-75

28. Leventhal H., Cleary P.D. The smoking problem: a review of the research and theory in behavioral risk modification. Psychol Bull 1980; 88: 370-405.

29. Ockene J.K., Mermelstein R.J., Bonollo D.S., Emmons K.M., Perkins K.A., Voorhees C.C., et al. Relapse and maintenance issues for smoking cessation. Health Psychology 2000; 19: $17-31$.

30. Kassel J.D., Stroud L.R., Paronis C.A. Smoking, stress, and negative affect: correlation, causation, and context across stages of smoking. Psychol Bull 2003; 129: 270-304.

31. Floyd R.L., Rimer B.K., Giovino G.A., Mullen P.D., Sullivan S.E. A review of smoking in pregnancy: effects on pregnancy outcomes and cessation efforts. Annu Rev Public Health 1993; 14: 379-411.

32. Jokela M., Hintsanen M., Hakulinen C., Batty G., Nabi H., Singh- Manoux A., et al. Association of personality with the development and persistence of obesity: a meta- analysis based on individual-participant data. Obesity Reviews 2013; 14: 315-23.

33. Jokela M., Elovainio M., Nyberg S.T., Tabák A.G., Hintsa T., Batty G.D., et al. Personality and Risk of Diabetes in Adults: Pooled Analysis of 5 Cohort Studies. Health Psychology 2014; 33: 1618-21. 
34. Jokela M., Pulkki-Råback L., Elovainio M., Kivimäki M. Personality traits as risk factors for stroke and coronary heart disease mortality: pooled analysis of three cohort studies. $J$ Behav Med 2014; 37; 881-9.

35. Hakulinen C., Elovainio M., Batty G.D., Virtanen M., Kivimäki M., Jokela M. Personality and Alcohol Consumption: Pooled Analysis of 72,949 Adults from Eight Cohort Studies. Drug Alcohol Depend 2015; 151: 110-4.

36. Jokela M., Batty G.D., Hintsa T., Elovainio M., Hakulinen C., Kivimäki M. Is personality associated with cancer incidence and mortality\&quest; An individual-participant metaanalysis of 2156 incident cancer cases among 42843 men and women. Br J Cancer 2014; 110: $1820-4$

37. Lahey B.B. Public health significance of neuroticism. Am Psychol 2009; 64: 241-256.

38. Chapman B.P., Hampson S., Clarkin J. Personality-informed interventions for healthy aging: Conclusions from a National Institute on Aging work group. Developmental psychology 2014; 50: 1426-41.

39. Conrod P.J., Castellanos-Ryan N., Mackie C. Long-term effects of a personality-targeted intervention to reduce alcohol use in adolescents. J Consult Clin Psychol 2011; 79: 296-306.

40. Kotov R., Gamez W., Schmidt F., Watson D. Linking "big” personality traits to anxiety, depressive, and substance use disorders: A meta-analysis. Psychol Bull 2010; 136: 768-821.

41. Hakulinen C., Elovainio M., Pulkki-Råback L., Virtanen M., Kivimäki M., Jokela M. PERSONALITY AND DEPRESSIVE SYMPTOMS: INDIVIDUAL PARTICIPANT META-ANALYSIS OF 10 COHORT STUDIES. 2015. doi: 10.1002/da.22376 
42. Grant B.F., Hasin D.S., Chou S.P., Stinson F.S., Dawson D.A. Nicotine dependence and psychiatric disorders in the United States: results from the national epidemiologic survey on alcohol and related conditions. Arch Gen Psychiatry 2004; 61: 1107-15.

43. Connor Gorber S., Schofield-Hurwitz S., Hardt J., Levasseur G., Tremblay M. The accuracy of self-reported smoking: a systematic review of the relationship between selfreported and cotinine-assessed smoking status. Nicotine Tob Res 2009; 11: 12-24.

44. Cervone D. Personality architecture: Within-person structures and processes. Anпи Rev Psychol 2005; 56: 423-52.

45. Block J. A contrarian view of the five-factor approach to personality description. Psychol Bull 1995; 117: 187-215.

46. Jokela M., Batty G.D., Nyberg S.T., Virtanen M., Nabi H., Singh-Manoux A., et al. The Authors Reply. Am J Epidemiol 2014; 179: 792-3. 


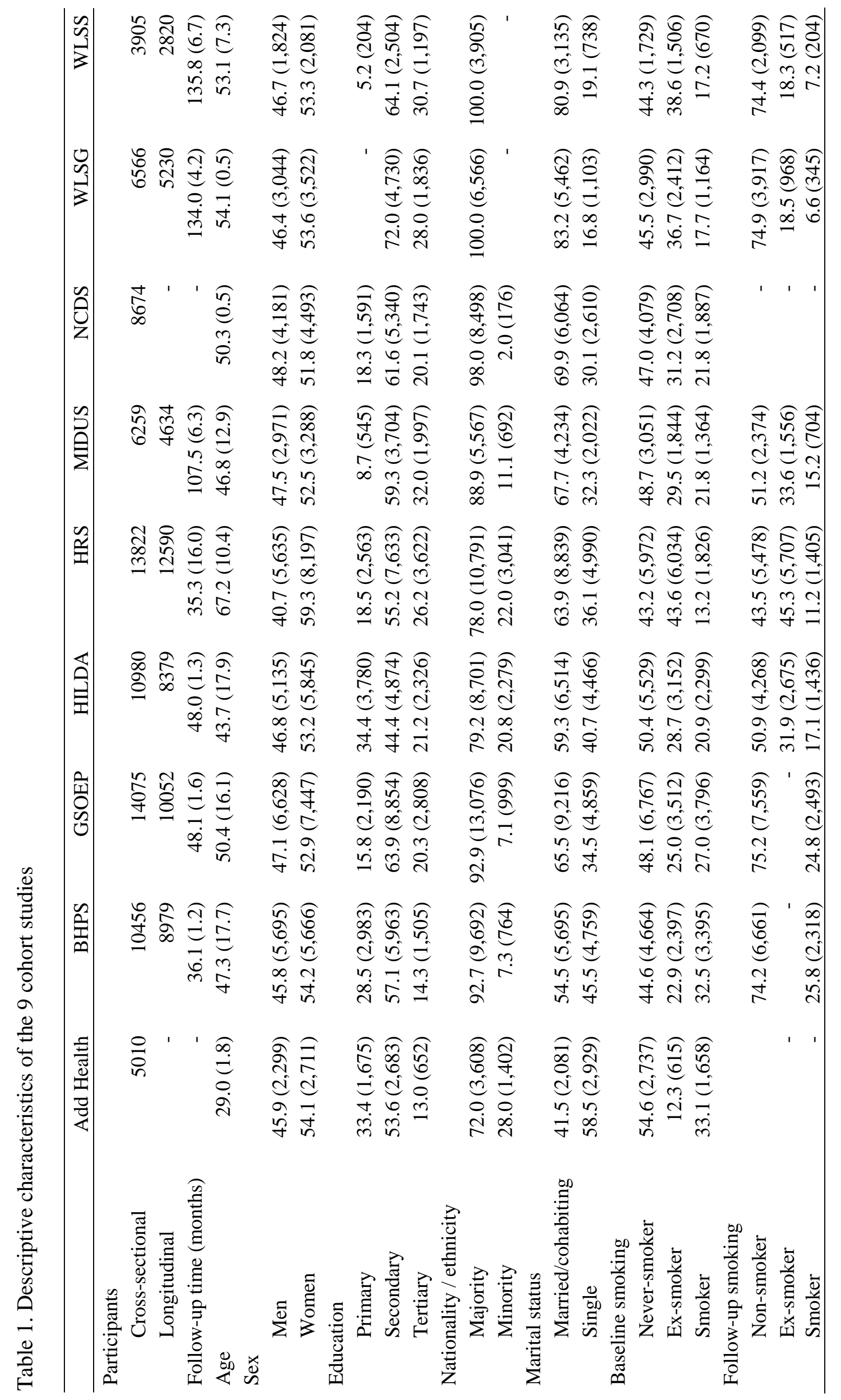




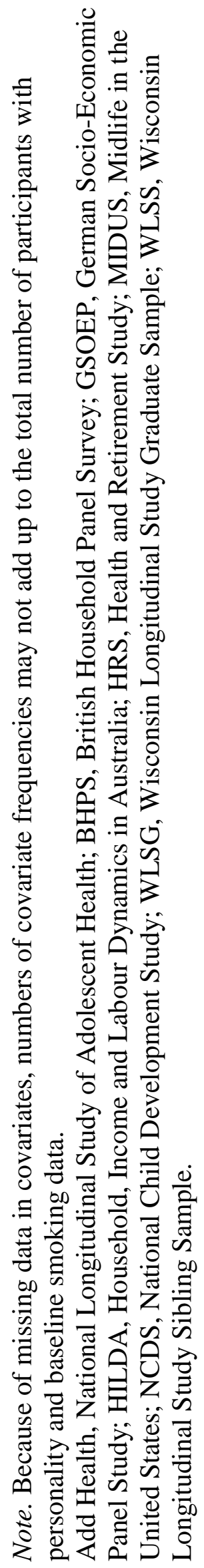




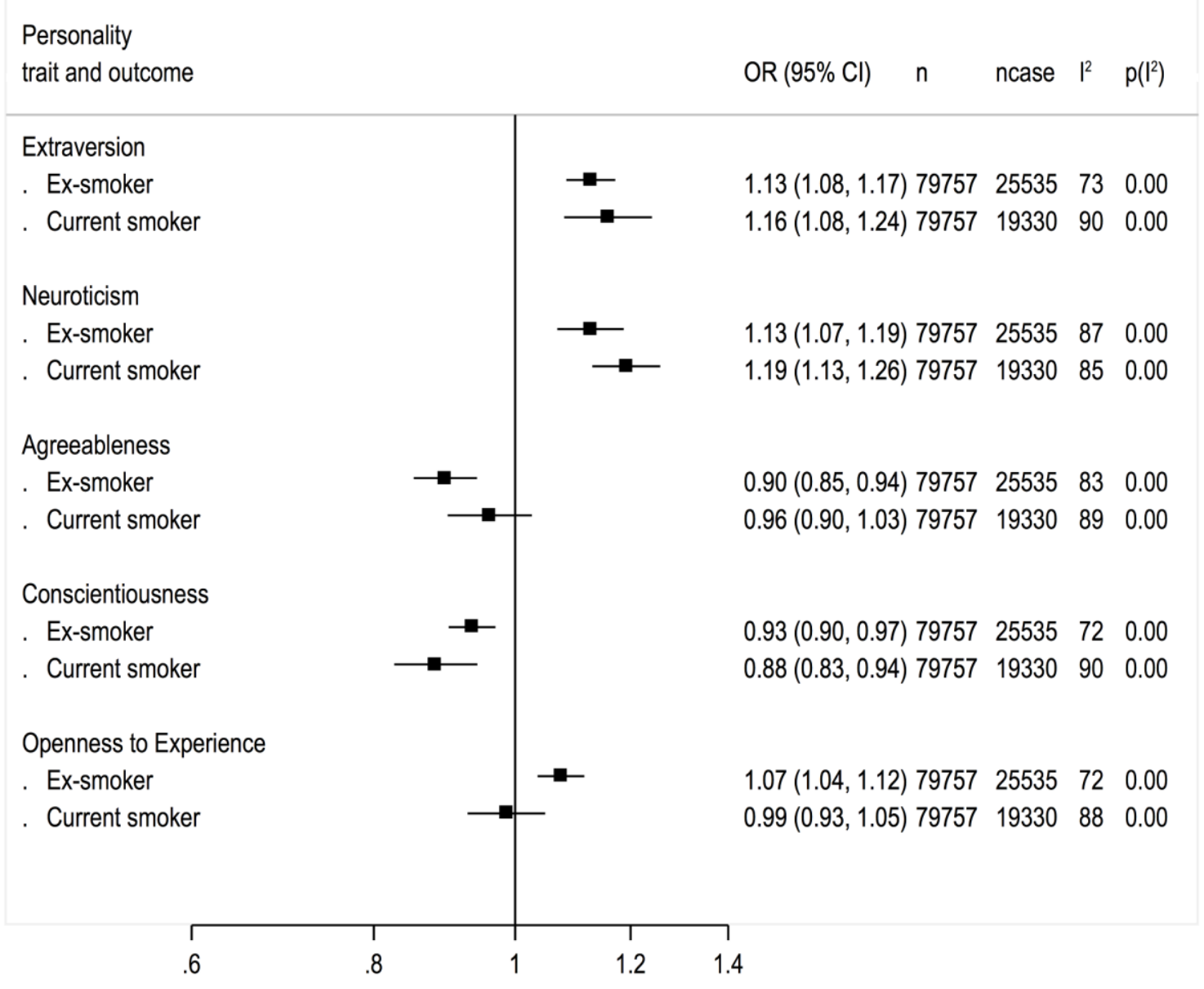

Figure 1. Cross-sectional associations between personality traits and current smoking status at the baseline. Values are odds ratios per 1 standard deviation increment in personality trait. Personality traits are adjusted for each other in addition to sex, age and race/ethnicity. 
Outcome and

personality trait

OR $(95 \% \mathrm{Cl}) \quad \mathrm{I}^{2} \quad \mathrm{p}\left(\mathrm{l}^{2}\right)$

Smoking initiation

. Extraversion

. Neuroticism

Agreeableness

Conscientiousness

Openness to Experience

Smoking relapse

. Extraversion

. Neuroticism

Agreeableness

- Conscientiousness

- Openness to Experience

Smoking cessation

. Extraversion

- Neuroticism

Agreeableness

- Conscientiousness

- Openness to Experience

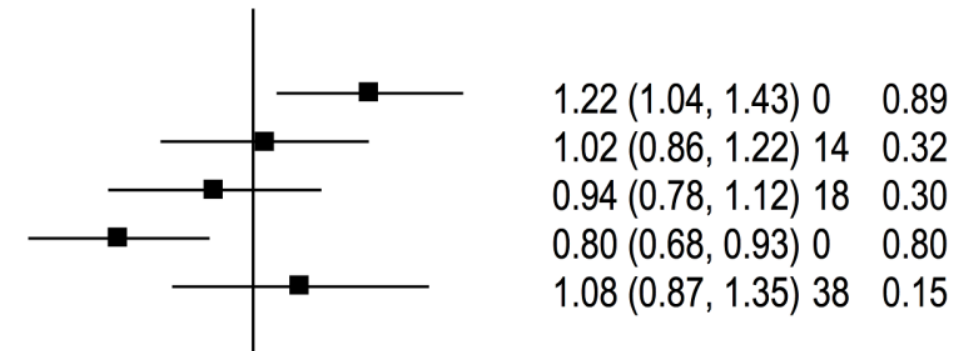

$1.03(0.90,1.18) 55 \quad 0.04$

$1.16(1.04,1.30) 40 \quad 0.13$

$1.09(0.98,1.21) 20 \quad 0.28$

$0.93(0.85,1.01) 0 \quad 0.90$

$1.07(0.98,1.17) 2 \quad 0.41$

$1.01(0.94,1.08) 31 \quad 0.19$

$0.91(0.87,0.96) 0 \quad 0.60$

$1.01(0.96,1.06) 0 \quad 0.65$

$1.00(0.91,1.09) 65 \quad 0.01$

$1.04(0.98,1.09) 0 \quad 0.82$

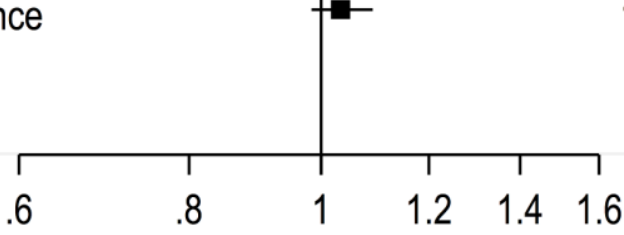

Figure 2. Longitudinal associations between personality traits and smoking initiation, smoking relapse among non-smokers at the baseline, and smoking cessation among smokers at the baseline. Values are odds ratios per 1 standard deviation increment in personality trait. Personality traits are adjusted for each other in addition to sex, age, race/ethnicity, and follow-up time. 
Personality and smoking: Individual-Participant Meta-Analysis of 9 cohort studies

SUPPLEMENT APPENDIX

1. Cohort descriptions

2. Acknowledgements

3. Supplement Tables 1, 2, 3, 4, 5 and 6

4. Supplement Figures 1, 2, 3, 4, and 5

5. References 


\section{$\underline{\text { National Longitudinal Study of Adolescent Health (Add Health) }}$}

The National Longitudinal Study of Adolescent Health (Add Health) is a longitudinal study of a nationally representative sample of adolescents in grades 7-12 in the United States during the 1994-1995 school year (1). Add Health combines longitudinal survey data on respondents' social, economic, psychological and physical well-being with contextual data on the family, neighborhood, community, school, friendships, peer groups, and romantic relationships, providing unique opportunities to study how social environments and behaviors in adolescence are linked to health and achievement outcomes in young adulthood. Wave I of the study began collecting data during the 1994-1995 school year, when the participants were in grades 7-12, and the most recent wave of data (Wave IV) was collected in 2008 when the participants were between the ages of 24-32 years old.

Personality was measured in the $4^{\text {th }}$ data collection wave in 2008 using a 20-item Five Factor Model personality instrument (2), 4 items per trait rated on a 5-point rating scale. Cronbach alpha reliabilities were 0.71 for extraversion, 0.63 for emotional stability, 0.70 for agreeableness, 0.65 for conscientiousness, and 0.65 for openness to experience. Personality scales were calculated for individuals with no missing values in the 4 items, resulting in a sample of 5,026 participants with full personality data at baseline.

The following three questions were used to define participants' current smoking status ( 0 =never-smoker, 1 =ex-smoker, 2 =current smoker): "Have you ever smoked cigarettes regularly--that is, at least one cigarette every day for 30 days?”, “During the past 30 days, on how many days did you smoke cigarettes?" and "During the past 30 days, on the days you smoked, how many cigarettes did you smoke each day?”. Information on marital status ( $0=$ single, $1=$ married/cohabiting) and race/ethnicity ( $0=$ white, non-Hispanic; $1=$ =other) were derived from the participants' self-reports. Educational level was determined on the basis of the highest achieved grade $(0=$ primary education, $1=$ secondary education, $3=$ =tertiary education).

Study website:

http://www.cpc.unc.edu/projects/addhealth 


\section{British Household Panel Survey (BHSP)}

The British Household Panel Survey (BHPS) is a longitudinal survey of a nationally representative sample of over 5000 British households with annual follow-ups (3). The original cohort included 10,264 individuals aged 16-97 at baseline in 1991, and was based on a clustered, stratified sample of addresses throughout Great Britain south of the Caledonian Canal (excluding North of Scotland and Northern Ireland). New participants have been included in the sample over the years if they are born to original sample member, if they have moved into a household in the original sample, or if a member of the original sample moves into a new household with one or more new people. In addition, the sample was enriched with additional recruitment of participants at waves 9 and 11, from Scotland and Wales, and from Northern Ireland, respectively, so extending the sample to cover the whole UK. The most recent $\left(18^{\text {th }}\right)$ follow-up of the BHPS was carried out in 2008-2009, after which the cohort has become part of the larger Understanding Society Study.

Personality was assessed in the $15^{\text {th }}$ data collection wave in 2005 using a brief, 15item version of the Big Five Inventory $(4,5)$ with three items assessing each personality trait, rated on a 7-point scale. Cronbach alpha reliabilities were 0.54 for extraversion, 0.68 for emotional stability, 0.53 for agreeableness, 0.51 for conscientiousness, and 0.67 for openness to experience. Personality scales were calculated for individuals with no missing items in the scale.

Current smoking status ( $0=$ never-smoker, $1=\mathrm{ex}$-smoker, $2=$ current smoker) was based on the following two questions: "Do you smoke cigarettes?” and "Have you ever smoked cigarettes regularly, that is at least one cigarette a day?”. The latter question was asked in the wave 12 . Information on marital status ( $0=$ single, $1=$ married/cohabiting) was derived from the participants' self-reports. Data on race/ethnicity was based on participants' self-reports and was coded as a dichotomous variable ( $0=$ white, non-Hispanic; $1=$ other). Educational level was determined on the basis of the highest achieved grade $(0=$ primary education, $1=$ secondary education, $3=$ tertiary education).

Study website:

http://www.esds.ac.uk/longitudinal/access/bhps/L33196.asp

http://www.understandingsociety.org.uk/ 


\section{German Socio-Economic Panel Study (GSOEP)}

The German Socio-Economic Panel Study (GSOEP) is a longitudinal study of private households (6). The study started in 1984 in West Germany with two subsamples: Sample A, the main sample, covering the population of private households, and Subsample B, which oversampled the “guest worker households” with Turkish, Spanish, Italian, Greek and Yugoslavian household heads. The original sample included 5921 households and 12,245 individual respondents. Several additional samples have subsequently been integrated in the study, including a sample of Germans from the late East Germany in 1990 (2,179 households; 4,453 individuals), an immigrant sample in 1994/1995 (522 households; 1,078 individuals), a refreshment sample of existing subsamples in 1998 (1,056 households; 1,910 individuals), an “innovation” subsample again covering all existing subsamples in 2000 (6,043 households; 10,880 individuals), a high-income subsample of households with net earnings more than 4500 euros/month in 2002 (1,224 households; 2,671 individuals), a second refreshment sample covering all existing subsamples in 2006 (1,506 households; 2,616 individuals), and an "incentive” sample covering all existing subsamples in 2009 (1,531 households; 2,509 individuals). All household members aged 17 years or older are invited for interview, which are carried out annually. Altogether, a total of 34,881 individuals have participated in the study at least in one study wave.

Personality was assessed in the 22nd data collection wave in 2005 using the 15-item version of the Big Five Inventory (BFI) $(4,5,7)$. Information on current smoking status ( 0 =never-smoker, 1 =ex-smoker, 2 =current smoker) was based on the following two questions: “Currently Smoke?” and, in addition, a question about lifetime smoking history from a previous wave was used to determine whether participant had ever smoked. Marital status ( $0=$ single, $1=$ =married/cohabiting) was derived from the participants' self-reports. Data on race/ethnicity was based on participants' self-reports and was coded as a dichotomous variable ( $0=$ white, non-Hispanic; $1=$ other). Educational level was determined on the basis of the highest achieved grade $(0=$ primary education, $1=$ secondary education, $3=$ =tertiary education).

Study website:

http://www.diw.de/en/soep 
Household, Income and Labour Dynamics in Australia (HILDA) Survey

The Household, Income and Labour Dynamics in Australia (HILDA) Survey is a household-based panel study which began in 2001, developed particularly to collects information about economic and subjective wellbeing, labour market dynamics and family dynamics (8). The survey began with a large national probability sample of Australian households occupying private dwellings ( $\mathrm{n}=7,682$ households with 19,914 individuals at baseline). All members of the households providing at least one interview in wave 1 form the basis of the panel to be pursued in each subsequent wave. Interviews are conducted annually with all adult members of each household. The sample has been gradually extended to include any new household members resulting from changes in the composition of the original households. From wave 9, new household members that arrived in Australia for the first time after 2001 were also added to the sample. Up to wave 10 carried out in 2010, a total of 28,547 individuals had participated in the study at least in one study wave.

Personality was assessed in wave 5 in 2005 using a 36-item Five Factor Personality self-reported inventory based on the Saucier’s and Goldberg’s Big Five Markers Scale (9) with 8 items for extraversion $(\alpha=0.77), 7$ items for neuroticism $(\alpha=0.79), 7$ items for agreeableness ( $\alpha=0.77), 7$ items for conscientiousness $(\alpha=0.79)$, and 6 items for openness to experience ( $\alpha=0.73$; the original item "traditional" was omitted from the scale because of a very low factor loading of 0.03 and a very low correlation of 0.02 between the item and a scale constructed from the rest of the items). The participants rated the items on a 7-point scale (1=Does not describe me at all, 7=Describes me very well). Personality sum scales were calculated for individuals with no more than 1 missing item in the scale, resulting in 11,091 individuals with full personality data at wave 5 .

Current smoking status ( $0=$ never-smoker, $1=$ ex-smoker, $2=$ current smoker) was based on the following question: "Do you smoke cigarettes or any other tobacco products?" Information on marital status ( $0=$ single, $1=$ married/cohabiting) was derived from the participants’ self-reports. Data on race/ethnicity was based on participants’ selfreports and was coded as a dichotomous variable ( $0=$ white, non-Hispanic; $1=$ other). Educational level was determined on the basis of the highest achieved grade $(0=$ primary education, $1=$ secondary education, $3=$ =tertiary education).

Study website:

http://www.melbourneinstitute.com/hilda/ 


\section{Health and Retirement Study (HRS)}

The HRS is a nationally representative longitudinal study of more than 30,000 individuals representing the U.S. population older than 50 years (10). Telephone or in-person interviews are conducted every 2 years, administered under the NIA and the University of Michigan’s Institute for Social Research. As of 1998, the HRS consists of 4 sources of data collection: (A) The original HRS began as two distinct surveys that were merged in 1998, and are. The original HRS was initially administered in 1992 to a nationally representative sample of Americans born in the years 1931 through 1941. In the case of married couples, both spouses (including spouses who were younger than 51 or older than 61) were also interviewed; (B) The second survey, originally referred to as the Study of Assets and Health Dynamics Among the Oldest Old (AHEAD), was first administered in 1993 to a nationally representative sample of Americans born in 1923 or earlier $(n=8,000)$ and merged with the HRS in 1998. In the case of married couples, interviews were conducted with both spouses; (3) In 1998, a subsample of individuals born between 1924 and 1930, referred to as Children of the Depression Age (CODA) was added to HRS; (4) Another subsample consisting of people born between 1942 and 1947 (War Baby cohort) was added to replenish the sample of people in their early 50s as the original HRS cohort aged. The Health Sciences Institutional Review Board at the University of Michigan approved the HRS.

Personality was measured using a self-reported instrument adapted from the MIDUS study with 5 items for extroversion $(\alpha=0.74), 4$ items for emotional stability $(\alpha=0.63), 5$ items for agreeableness $(\alpha=0.78), 5$ items for conscientiousness $(\alpha=0.63)$, and 7 items for openness to experience $(\alpha=0.79)$, rated on a 4-point rating scale (11). Mean scores for personality scales were calculated for individuals with a maximum of 1 missing item in the scale, resulting in 14,549 participants with full personality data at baseline. The personality instrument was administered to half of the sample in 2006 and to the other half in 2008. Thus, the study baseline was 2006 for half of the sample and 2008 for the other half of the sample. Baseline data on other covariates were derived from the year of personality assessment.

Information on current smoking status ( $0=$ never-smoker, $1=$ ex-smoker, $2=$ current smoker) was derived from the following questions: "Have you ever smoked cigarettes?” and “Do you smoke cigarettes now?” Information on marital status $(0=$ single, $1=$ married/cohabiting) was derived from the self-reports. Data on race/ethnicity was based on participants' self-reports and was coded as a dichotomous variable $(0=$ white, nonHispanic; 1=other). Educational level was determined on the basis of the highest achieved grade $(0=$ primary education, $1=$ secondary education, $3=$ tertiary education). 
Online supplement: Personality and smoking

Study website:

http://hrsonline.isr.umich.edu 


\section{Midlife in the United States (MIDUS)}

The MacArthur Foundation Survey of Midlife Development in the United States (MIDUS) is based on a nationally representative random-digit-dial sample of non-institutionalized, English-speaking adults, aged 25 to 74 years, selected from working telephone banks in the coterminous United States in 1995-1996 (12). The total original sample $(n=7108)$ includes main respondents $(n=3487)$, their siblings $(n=950)$, a city oversample $(n=757)$, and a twin subsample ( $\mathrm{n}=1914)$. Data were collected in a telephone interview and with a mail questionnaire. A follow-up study of the original cohort was conducted in 2004-2005.

Personality was assessed at baseline with a model based on the Five Factor Model (11) including 5 items of extraversion $(\alpha=0.78), 4$ items for neuroticism $(\alpha=0.75), 5$ items for agreeableness ( $\alpha=0.81), 4$ items for conscientiousness $(\alpha=0.56)$, and 7 items for openness to experience $(\alpha=0.78)$. Items were rated using a 4-point rating scale on how well different adjectives described them (1=not at all, $4=\mathrm{a}$ lot). Full data on personality traits at baseline were available for 6,261 participants.

The following two questions were used to define participants' current smoking status ( 0 =never-smoker, 1 =ex-smoker, 2 =current smoker): "Have you ever smoked cigarettes regularly -- that is, at least a few cigarettes every day?” and “Do you smoke cigarettes regularly NOW?” Marital status ( $0=$ single, $1=$ =married/cohabiting) was derived from the selfrepots. Data on race/ethnicity was based on participants' self-reports and was coded as a dichotomous variable ( $0=$ white, non-Hispanic; $1=$ other). Educational level was determined on the basis of the highest achieved grade $(0=$ primary education, $1=$ secondary education, $3=$ tertiary education).

Study website:

http://www.midus.wisc.edu/ 


\section{National Child Development Study (NCDS)}

The nationally representative 1958 British birth cohort study (also known as the British National Child Development Study (13). The original participants were 17,634 individuals born in England, Wales, and Scotland during one week in March 1958. Data have been collected in follow-up phases at ages 7, 11, 16, 23, 33, 42, 46, and 50. Written informed consent was obtained from the parents for childhood measurements and ethical approval for the study was obtained from the South East Multi-Centre Research Ethics Committee.

Personality was measured at age 50 using the 50-item Big Five model of the International Personality Item Pool (IPIP, (14) ) with 10 items per personality trait rated on a 5-point rating scale. The Cronbach alpha reliabilites were 0.87 for extraversion, 0.88 for neuroticism, 0.81 for agreeableness, 0.77 for conscientiousness, and 0.78 for openness to experience. A mean score for each personality trait was calculated if no more than two items in the scale were missing, resulting in 8,697 participants with full data at baseline.

Information on current smoking status ( $0=$ never-smoker, $1=$ ex-smoker, $2=$ current smoker) was based on the following question: "Do you smoke tobacco products such as cigarettes, cigars or a pipe at all nowadays?” Marital status $(0=$ single, $1=$ married/cohabiting), was derived from the participants' self-reports. Data on race/ethnicity was based on participants' self-reports and was coded as a dichotomous variable $(0=$ white, non-Hispanic; 1=other). Educational level was determined on the basis of the highest achieved grade ( $0=$ primary education, $1=$ secondary education, $3=$ =tertiary education).

Study website:

http://www.esds.ac.uk/longitudinal/access/ncds/l33004.asp 


\section{Wisconsin Longitudinal Study (WLS), Graduate and Sibling Samples}

Graduate sample. The Wisconsin Longitudinal Study has followed a random sample of 10317 participants (5326 women, 4991 men) who were born between 1937 and 1940 and who graduated from Wisconsin high schools in 1957 (15). After baseline data collection in 1957, survey data have been collected from the participants or their parents in 1964, 1975, 1992/3, and 2003/5. The present study used data from the 1993 follow-up. The WLS sample is broadly representative of white, non-Hispanic American men and women who have completed at least a high school education (among Americans aged 50 to 54 in 1990 and 1991, approximately 66 percent were non-Hispanic white persons who completed at least 12 years of schooling). It is estimated that about 75 percent of Wisconsin youth graduated from high school in the late 1950s - everyone in the primary WLS sample graduated from high school.

Sibling sample. In addition to the main sample of the 1957 high school graduates, the WLS has also collected data on a selected sibling of a sample of the graduates. The data collection in adulthood has been very similar although not entirely identical for the siblings as for the graduates. For the present purposes, the sibling sample was analyzed separately from the graduate sample, because the sampling frame of the individuals for the graduate cohort and sibling cohort was considered to sufficiently to justify the decision of not combining the samples.

Personality data were collected in 1992-1994 via mail questionnaire including a 29version of the Big Five Inventory (BFI) $(3,4)$. Participants were asked whether they agreed or disagreed that certain personality descriptions fitted themselves using a 6-point rating scale. The Cronbach alpha reliabilities were 0.76 for extraversion in graduates/ 0.65 in siblings for extraversion, 0.78/0.63 for neuroticism, 0.69/0.70 for agreeableness, 0.64/0.70 for conscientiousness, and $0.61 / 0.70$ for openness to experience. A mean score for a trait was calculated if no more than 2 items of the scale were missing, resulting in 6,674 WLS graduates and 3,969 WLS siblings with full personality data at baseline.

Information on current smoking status $(0=$ never-smoker, $1=$ ex-smoker, $2=$ current smoker) was based on the following questions: "Have you ever smoked cigarettes regularly?" and “Do you smoke regularly now?” Marital status (0=single, 1=married/cohabiting) was derived from the participants' self-reports. Educational level was determined on the basis of the highest achieved grade $(0=$ primary education, $1=$ secondary education, $3=$ tertiary education). 
Online supplement: Personality and smoking

Study website:

http://www.ssc.wisc.edu/wlsresearch/ 


\section{$\underline{\text { Acknowledgements }}$}

The authors wish to gratefully thank the original collectors of the data, and the ESDS (Economic and Social Data Service; http://ukdataservice.ac.uk) and ICPSR (Inter-university Consortium for Political and Social Research; www.icpsr.umich.edu) for making the data available.

The data used in this study were made available through the UK Data Service. The data were originally collected by the ESRC Research Centre on Micro-Social Change at the University of Essex (now incorporated within the Institute for Social and Economic Research). Neither the original collectors of the data nor the Service bear any responsibility for the analyses or interpretations presented here.

This research uses data from Add Health, a program project designed by J. Richard Udry, Peter S. Bearman, and Kathleen Mullan Harris, and funded by a grant P01-HD31921 from the Eunice Kennedy Shriver National Institute of Child Health and Human Development, with cooperative funding from 17 other agencies. Special acknowledgment is due Ronald R. Rindfuss and Barbara Entwisle for assistance in the original design. Persons interested in obtaining data files from Add Health should contact Add Health, Carolina Population Center, 123 W. Franklin Street, Chapel Hill, NC 27516-2524 (addhealth@unc.edu).

This paper uses unit record data from the Household, Income and Labour Dynamics in Australia (HILDA) Survey. The HILDA Project was initiated and is funded by the Australian Government Department of Families, Housing, Community Services and Indigenous Affairs (FaHCSIA) and is managed by the Melbourne Institute of Applied Economic and Social Research (Melbourne Institute). The findings and views reported in this paper, however, are those of the author and should not be attributed to either FaHCSIA or the Melbourne Institute.

The research uses data from the Wisconsin Longitudinal Study (WLS) of the University of Wisconsin-Madison. Since 1991, the WLS has been supported principally by the National Institute on Aging (AG-9775 and AG-21079), with additional support from the Vilas Estate Trust, the National Science Foundation, the Spencer Foundation, and the Graduate School of the University of Wisconsin-Madison. A public use file of data from the Wisconsin Longitudinal Study is available from the Wisconsin Longitudinal Study, University of Wisconsin-Madison, 1180 Observatory Drive, Madison, Wisconsin 53706 and at http://www.ssc.wisc.edu/wlsresearch/data/. The interpretations, opinions, and inferences based on the data are solely the responsibility of the authors. 
Supplementary Table 1. Subgroup analyses of cross-sectional associations between personality traits and smoking at the baseline

\begin{tabular}{|c|c|c|c|c|c|}
\hline Subgroups & Extraversion & Neuroticism & Agreeableness & Conscientiousness & Openness \\
\hline \multicolumn{6}{|l|}{ Sex } \\
\hline Men & $1.14(1.06,1.21)$ & $1.16(1.09,1.24)$ & $0.95(0.89,1.01)$ & $0.88(0.82,0.93)$ & $0.96(0.90,1.02)$ \\
\hline Women & $1.19(1.10,1.29)$ & $1.19(1.12,1.26)$ & $0.94(0.85,1.02)$ & $0.87(0.81,0.93)$ & $0.98(0.90,1.06)$ \\
\hline$I^{2}(p$-value $)$ & $0 \%(0.37)$ & $0 \%(0.60)$ & $0 \%(0.75)$ & $0 \%(0.91)$ & $0 \%(0.67)$ \\
\hline \multicolumn{6}{|l|}{ Age } \\
\hline$<40$ & $1.22(1.14,1.30)$ & $1.23(1.16,1.31)$ & $0.93(0.87,0.99)$ & $0.85(0.79,0.90)$ & $0.96(0.90,1.01)$ \\
\hline $40-65$ & $1.14(1.05,1.24)$ & $1.12(1.05,1.20)$ & $0.98(0.89,1.07)$ & $0.87(0.79,0.94)$ & $0.98(0.89,1.07)$ \\
\hline $65^{+}$ & $1.02(0.87,1.17)$ & $1.07(0.93,1.21)$ & $0.90(0.76,1.03)$ & $0.95(0.82,1.08)$ & $0.90(0.77,1.03)$ \\
\hline$I^{2}$ (p-value $)$ & $66 \%(0.05)$ & $69 \%(0.04)$ & $0 \%(0.54)$ & $0 \%(0.37)$ & $0 \%(0.59)$ \\
\hline \multicolumn{6}{|l|}{ Education } \\
\hline Primary & $1.10(1.00,1.19)$ & $1.11(1.02,1.20)$ & $0.95(0.87,1.03)$ & $0.89(0.82,0.97)$ & $1.01(0.92,1.09)$ \\
\hline Secondary & $1.13(1.02,1.23)$ & $1.17(1.10,1.23)$ & $0.91(0.86,0.97)$ & $0.91(0.85,0.96)$ & $1.09(1.00,1.18)$ \\
\hline Tertiary & $1.18(1.00,1.36)$ & $1.10(0.97,1.23)$ & $0.92(0.80,1.04)$ & $0.83(0.73,0.93)$ & $1.20(1.04,1.36)$ \\
\hline$I^{2}$ (p-value $)$ & $0 \%(0.69)$ & $0 \%(0.51)$ & $0 \%(0.71)$ & $0 \%(0.44)$ & $60 \%(0.08)$ \\
\hline \multicolumn{6}{|l|}{ Marital status } \\
\hline Married/Cohabiting & $1.18(1.09,1.26)$ & $1.16(1.09,1.22)$ & $0.94(0.87,1.01)$ & $0.90(0.84,0.95)$ & $0.95(0.90,1.01)$ \\
\hline Single & $1.18(1.10,1.26)$ & $1.21(1.14,1.29)$ & $0.94(0.88,1.00)$ & $0.90(0.84,0.96)$ & $0.94(0.88,1.01)$ \\
\hline$I^{2}$ (p-value $)$ & $0 \%(0.89)$ & $18 \%(0.27)$ & $0 \%(0.97)$ & $0 \%(0.99)$ & $0 \%(0.84)$ \\
\hline \multicolumn{6}{|l|}{ Ethnicity/Nationality } \\
\hline Majority & $1.17(1.09,1.25)$ & $1.18(1.11,1.26)$ & $0.95(0.88,1.01)$ & $0.88(0.82,0.94)$ & $0.97(0.91,1.03)$ \\
\hline Minority & $1.11(0.96,1.26)$ & $1.21(1.06,1.36)$ & $0.95(0.82,1.08)$ & $0.87(0.76,0.99)$ & $1.00(0.87,1.14)$ \\
\hline$I^{2}$ (p-value $)$ & $0 \%(0.51)$ & $0 \%(0.77)$ & $0 \%(0.96)$ & $0 \%(0.91)$ & $0 \%(0.67)$ \\
\hline
\end{tabular}

Note. Values are odds ratios (and 95\% confidence intervals) of logistic regression analysis predicting smoking at the baseline in the different subgroups pooled across studies. Statistical significance of subgroup differences is evaluated based on heterogeneity of the effect sizes $\left(\mathrm{I}^{2}\right)$ and their p-values. 
Supplementary Table 2. Subgroup analyses of cross-sectional associations between personality traits and being an exsmoker at the baseline

\begin{tabular}{|c|c|c|c|c|c|}
\hline Subgroups & Extraversion & Neuroticism & Agreeableness & Conscientiousness & Openness \\
\hline \multicolumn{6}{|l|}{ Sex } \\
\hline Men & $1.09(1.02,1.15)$ & $1.13(1.07,1.19)$ & $0.91(0.86,0.97)$ & $0.92(0.87,0.98)$ & $1.03(0.97,1.09)$ \\
\hline Women & $1.15(1.08,1.21)$ & $1.09(1.02,1.15)$ & $0.85(0.80,0.90)$ & $0.93(0.88,0.98)$ & $1.10(1.03,1.16)$ \\
\hline$I^{2}$ (p-value) & $38 \%(0.2)$ & $0 \%(0.37)$ & $63 \%(0.10)$ & $0 \%(0.81)$ & $59 \%(0.12)$ \\
\hline \multicolumn{6}{|l|}{ Age } \\
\hline$<40$ & $1.16(1.09,1.24)$ & $1.13(1.06,1.20)$ & $0.89(0.84,0.95)$ & $0.90(0.85,0.96)$ & $1.05(0.99,1.12)$ \\
\hline $40-65$ & $1.12(1.04,1.19)$ & $1.09(1.02,1.15)$ & $0.87(0.81,0.93)$ & $0.93(0.87,0.99)$ & $1.06(1.00,1.13)$ \\
\hline $65+$ & $1.04(0.94,1.14)$ & $1.08(0.99,1.16)$ & $0.90(0.82,0.98)$ & $0.93(0.85,1.01)$ & $1.09(1.00,1.19)$ \\
\hline$I^{2}$ (p-value) & $52 \%(0.12)$ & $0 \%(0.58)$ & $0 \%(0.8)$ & $0 \%(0.75)$ & $0 \%(0.76)$ \\
\hline \multicolumn{6}{|l|}{ Education } \\
\hline Primary & $1.10(1.00,1.20)$ & $1.07(0.99,1.16)$ & $0.90(0.82,0.97)$ & $0.96(0.88,1.03)$ & $1.06(0.98,1.15)$ \\
\hline Secondary & $1.10(1.04,1.16)$ & $1.11(1.05,1.17)$ & $0.88(0.83,0.93)$ & $0.95(0.90,1.00)$ & $1.08(1.02,1.14)$ \\
\hline Tertiary & $1.15(1.05,1.25)$ & $1.08(0.99,1.17)$ & $0.83(0.76,0.91)$ & $0.88(0.80,0.96)$ & $1.17(1.06,1.28)$ \\
\hline$I^{2}(p$-value $)$ & $0 \%(0.7)$ & $0 \%(0.78)$ & $0 \%(0.46)$ & $23 \%(0.27)$ & $22 \%(0.28)$ \\
\hline \multicolumn{6}{|l|}{ Marital status } \\
\hline Married/Cohabiting & $1.13(1.07,1.18)$ & $1.12(1.07,1.18)$ & $0.89(0.84,0.93)$ & $0.92(0.88,0.97)$ & $1.05(1.00,1.10)$ \\
\hline Single & $1.10(1.03,1.18)$ & $1.08(1.01,1.16)$ & $0.88(0.81,0.94)$ & $0.95(0.88,1.01)$ & $1.11(1.03,1.19)$ \\
\hline$I^{2}$ (p-value) & $0 \%(0.62)$ & $0 \%(0.4)$ & $0 \%(0.75)$ & $0 \%(0.54)$ & $42 \%(0.19)$ \\
\hline \multicolumn{6}{|l|}{ Ethnicity/Nationality } \\
\hline Majority & $1.13(1.08,1.17)$ & $1.12(1.05,1.18)$ & $0.88(0.84,0.92)$ & $0.93(0.90,0.97)$ & $1.06(1.02,1.11)$ \\
\hline Minority & $1.10(0.95,1.25)$ & $1.10(0.97,1.24)$ & $0.94(0.81,1.08)$ & $0.94(0.81,1.06)$ & $1.11(0.96,1.25)$ \\
\hline$I^{2}(p$-value $)$ & $0 \%(0.75)$ & $0 \%(0.83)$ & $0 \%(0.35)$ & $0 \%(0.96)$ & $0 \%(0.56)$ \\
\hline
\end{tabular}

Note. Values are odds ratios (and 95\% confidence intervals) of logistic regression analysis predicting smoking at the baseline in the different subgroups pooled across studies. Statistical significance of subgroup differences is evaluated based on heterogeneity of the effect sizes $\left(\mathrm{I}^{2}\right)$ and their p-values. 
Supplementary Table 3. Subgroup analyses of longitudinal associations between personality traits and smoking initiation

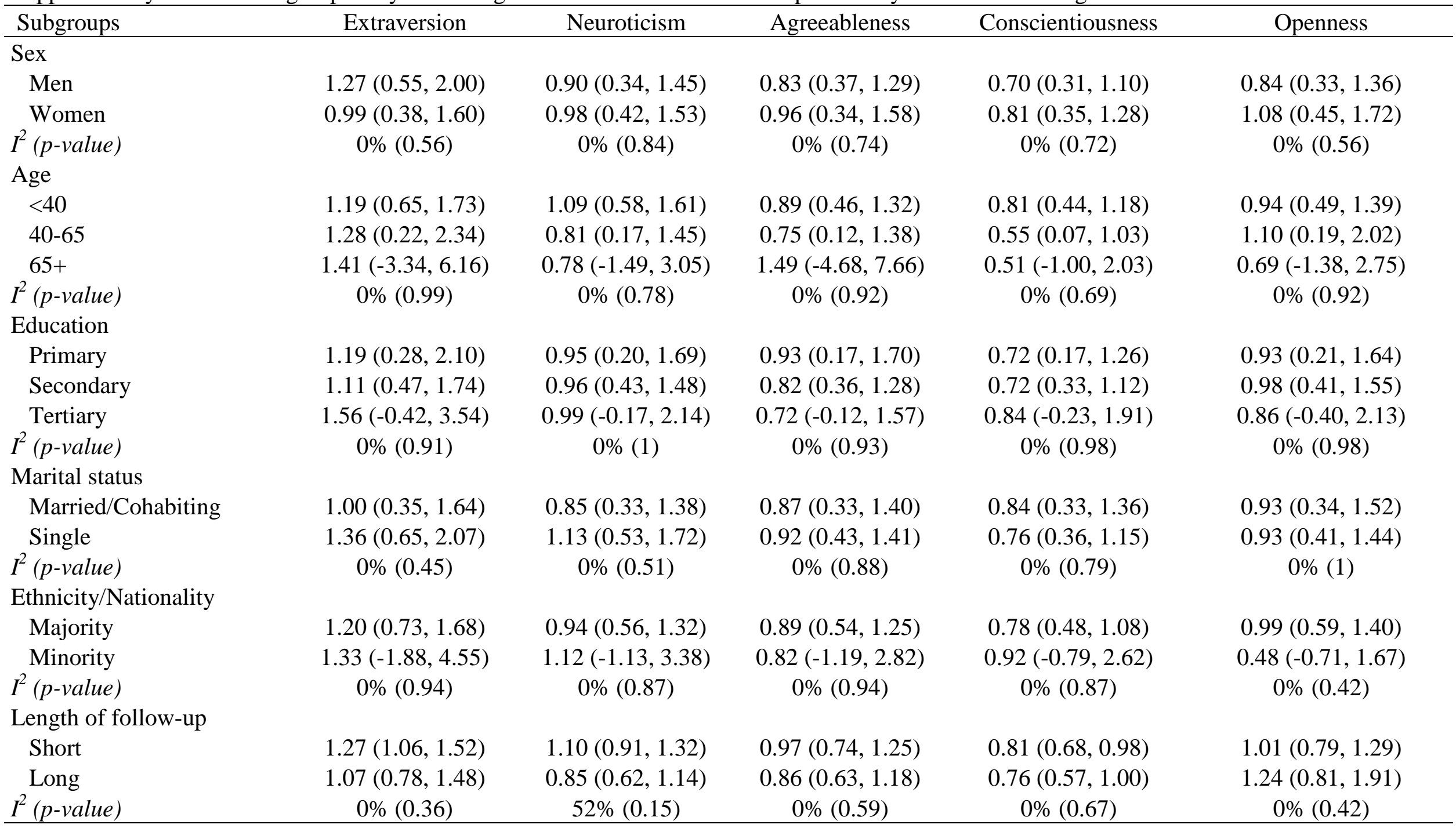

Note. Values are odds ratios (and 95\% confidence intervals) of logistic regression analysis predicting smoking at the baseline in the different 
subgroups pooled across studies. Statistical significance of subgroup differences is evaluated based on heterogeneity of the effect sizes $\left(\mathrm{I}^{2}\right)$ and their p-values. 
Supplementary Table 4. Subgroup analyses of longitudinal associations between personality traits and smoking relapse

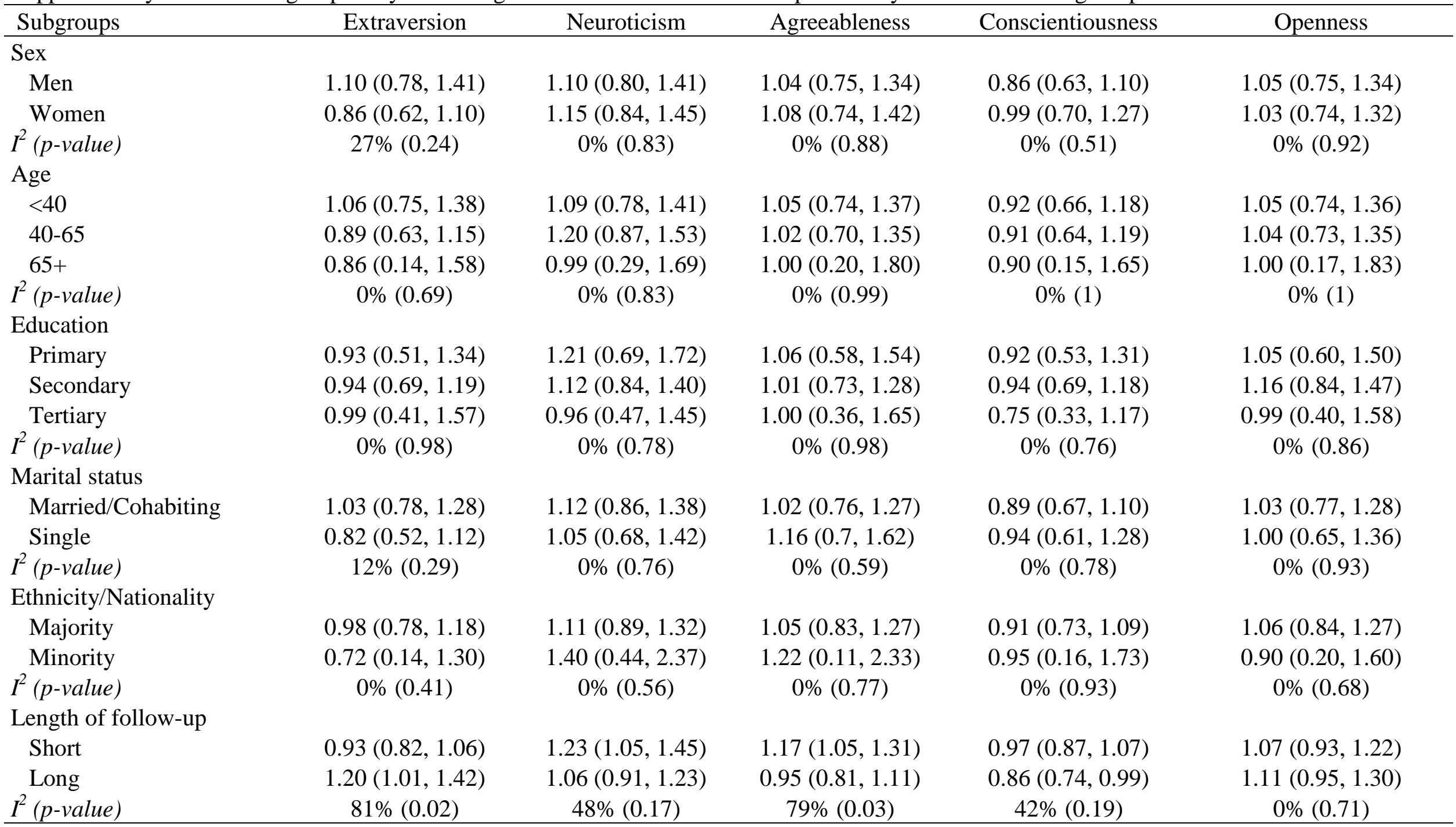

Note. Values are odds ratios (and 95\% confidence intervals) of logistic regression analysis predicting smoking at the baseline in the different 
subgroups pooled across studies. Statistical significance of subgroup differences is evaluated based on heterogeneity of the effect sizes $\left(\mathrm{I}^{2}\right)$ and their p-values. 
Supplementary Table 5. Subgroup analyses of longitudinal associations between personality traits and smoking cessation

\begin{tabular}{|c|c|c|c|c|c|}
\hline Subgroups & Extraversion & Neuroticism & Agreeableness & Conscientiousness & Openness \\
\hline \multicolumn{6}{|l|}{ Sex } \\
\hline Men & $1.10(0.78,1.41)$ & $1.10(0.80,1.41)$ & $1.04(0.75,1.34)$ & $0.86(0.63,1.10)$ & $1.05(0.75,1.34)$ \\
\hline Women & $0.86(0.62,1.10)$ & $1.15(0.84,1.45)$ & $1.08(0.74,1.42)$ & $0.99(0.70,1.27)$ & $1.03(0.74,1.32)$ \\
\hline \multicolumn{6}{|l|}{ Age } \\
\hline$<40$ & $1.06(0.75,1.38)$ & $1.09(0.78,1.41)$ & $1.05(0.74,1.37)$ & $0.92(0.66,1.18)$ & $1.05(0.74,1.36)$ \\
\hline $40-65$ & $0.89(0.63,1.15)$ & $1.20(0.87,1.53)$ & $1.02(0.70,1.35)$ & $0.91(0.64,1.19)$ & $1.04(0.73,1.35)$ \\
\hline \multicolumn{6}{|l|}{ Education } \\
\hline Primary & $0.93(0.51,1.34)$ & $1.21(0.69,1.72)$ & $1.06(0.58,1.54)$ & $0.92(0.53,1.31)$ & $1.05(0.60,1.50)$ \\
\hline Secondary & $0.94(0.69,1.19)$ & $1.12(0.84,1.40)$ & $1.01(0.73,1.28)$ & $0.94(0.69,1.18)$ & $1.16(0.84,1.47)$ \\
\hline Tertiary & $0.99(0.41,1.57)$ & $0.96(0.47,1.45)$ & $1.00(0.36,1.65)$ & $0.75(0.33,1.17)$ & $0.99(0.40,1.58)$ \\
\hline$I^{2}(p$-value $)$ & $0 \%(0.91)$ & $0 \%(0.93)$ & $0 \%(0.42)$ & $0 \%(0.92)$ & $0 \%(0.73)$ \\
\hline \multicolumn{6}{|l|}{ Marital status } \\
\hline \multicolumn{6}{|l|}{ Ethnicity/Nationality } \\
\hline Majority & $0.98(0.78,1.18)$ & $1.11(0.89,1.32)$ & $1.05(0.83,1.27)$ & $0.91(0.73,1.09)$ & $1.06(0.84,1.27)$ \\
\hline Minority & $0.72(0.14,1.30)$ & $1.40(0.44,2.37)$ & $1.22(0.11,2.33)$ & $0.95(0.16,1.73)$ & $0.90(0.20,1.60)$ \\
\hline$I^{2}(p$-value $)$ & $0 \%(0.63)$ & $0 \%(0.65)$ & $0 \%(0.95)$ & $0 \%(0.32)$ & $1 \%(0.31)$ \\
\hline \multicolumn{6}{|l|}{ Length of follow-up } \\
\hline Short & $1.04(0.96,1.12)$ & $0.92(0.86,0.97)$ & $1.00(0.94,1.06)$ & $1.01(0.88,1.16)$ & $1.04(0.98,1.10)$ \\
\hline Long & $0.94(0.84,1.06)$ & $0.90(0.81,0.99)$ & $1.05(0.94,1.17)$ & $0.98(0.88,1.09)$ & $1.02(0.92,1.14)$ \\
\hline$I^{2}$ (p-value) & $44 \%(0.18)$ & $0 \%(0.71)$ & $0 \%(0.39)$ & $0 \%(0.71)$ & $0 \%(0.75)$ \\
\hline
\end{tabular}


Note. Values are odds ratios (and 95\% confidence intervals) of logistic regression analysis predicting smoking at the baseline in the different subgroups pooled across studies. Statistical significance of subgroup differences is evaluated based on heterogeneity of the effect sizes $\left(\mathrm{I}^{2}\right)$ and their p-values. 
Supplementary Table 6. Comparison of the two-step and one-step individual participants meta-analysis results

\begin{tabular}{|c|c|c|c|c|}
\hline & Two-step & & One- & \\
\hline Smoking initiation & OR & $95 \% \mathrm{CI}$ & OR & $95 \% \mathrm{CI}$ \\
\hline Extraversion & 1.22 & $1.04,1.43$ & 1.33 & $1.09,1.61$ \\
\hline Neuroticism & 1.02 & $0.86,1.22$ & 1.04 & $0.85,1.26$ \\
\hline Agreeableness & 0.94 & $0.78,1.12$ & 0.90 & $0.74,1.10$ \\
\hline Conscientiousness & 0.80 & $0.68,0.93$ & 0.74 & $0.57,0.96$ \\
\hline Openness to Experience & 1.08 & $0.87,1.35$ & 1.12 & $0.90,1.38$ \\
\hline \multicolumn{5}{|l|}{ Smoking relapse } \\
\hline Extraversion & 1.03 & $0.90,1.18$ & 1.05 & $0.92,1.19$ \\
\hline Neuroticism & 1.16 & $1.04,1.30$ & 1.19 & $1.05,1.34$ \\
\hline Agreeableness & 1.09 & $0.98,1.21$ & 1.10 & $0.97,1.24$ \\
\hline Conscientiousness & 0.93 & $0.85,1.01$ & 0.93 & $0.85,1.03$ \\
\hline Openness to Experience & 1.07 & $0.98,1.17$ & 1.09 & $0.98,1.20$ \\
\hline \multicolumn{5}{|l|}{ Smoking cessation } \\
\hline Extraversion & 1.01 & $0.94,1.08$ & 1.00 & $0.93,1.07$ \\
\hline Neuroticism & 0.91 & $0.87,0.96$ & 0.92 & $0.87,0.98$ \\
\hline Agreeableness & 1.01 & $0.96,1.06$ & 1.02 & $0.93,1.12$ \\
\hline Conscientiousness & 1.00 & $0.91,1.09$ & 0.99 & $0.91,1.07$ \\
\hline Openness to Experience & 1.04 & $0.98,1.09$ & 1.03 & $0.97,1.10$ \\
\hline
\end{tabular}

Values are odds ratios (and 95\% confidence intervals) per 1 standard deviation increment in personality trait. Personality traits are adjusted for each other in addition to sex, age, race/ethnicity, and follow-up time. 


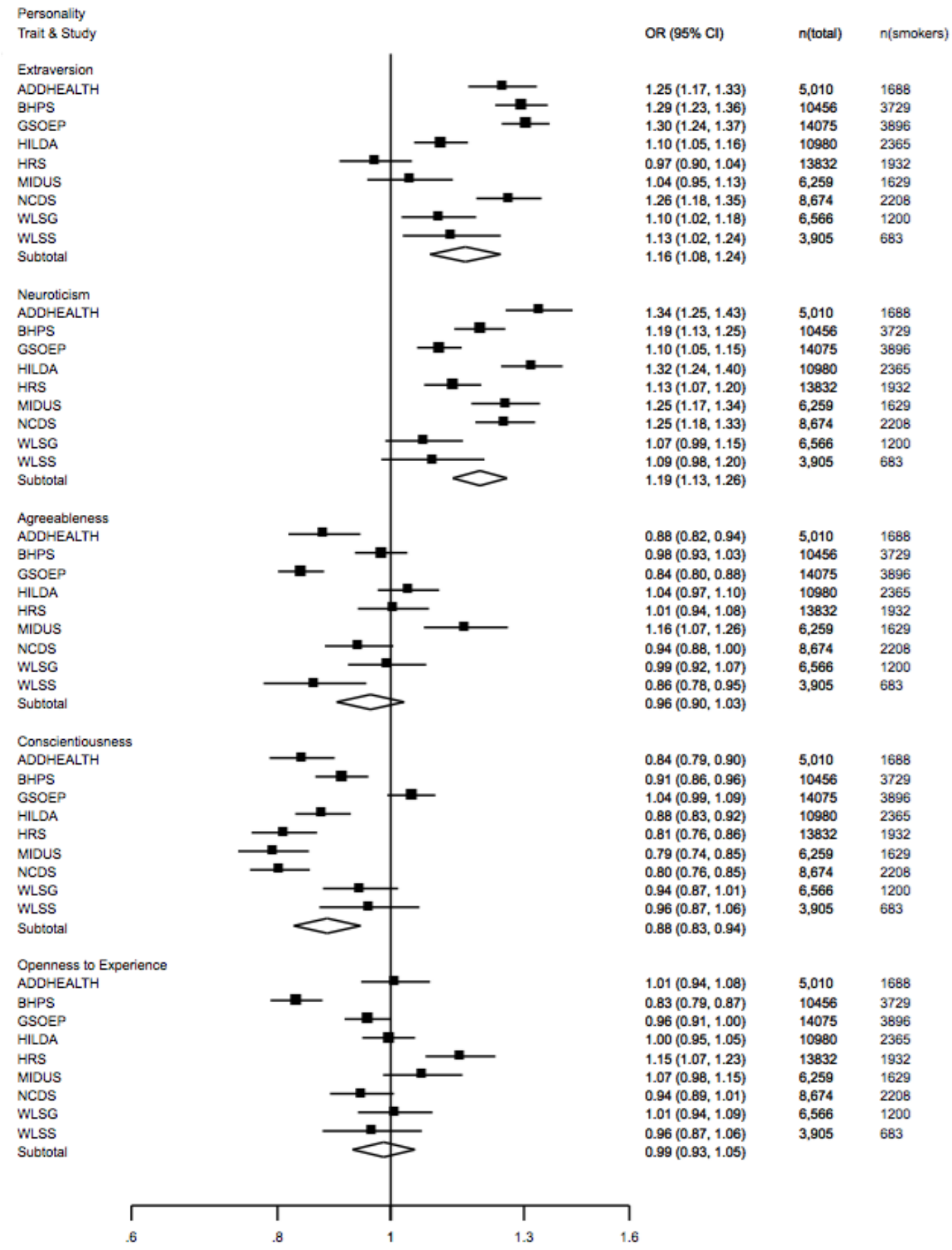

Supplemental Figure 1. Cross-sectional associations between the Five-Factor Model personality traits and smoking at the baseline. Values are odds ratios per 1 standard deviation increment in personality trait. Add Health, National Longitudinal Study of Adolescent Health; BHPS, British Household Panel Survey; GSOEP, German Socio-Economic Panel Study; HILDA, Household, Income and Labour Dynamics in Australia; HRS, Health and Retirement Study; MIDUS, Midlife in the United States; NCDS, National Child Development Study; 
WLSG, Wisconsin Longitudinal Study Graduate Sample; WLSS, Wisconsin Longitudinal Study Sibling Sample. 


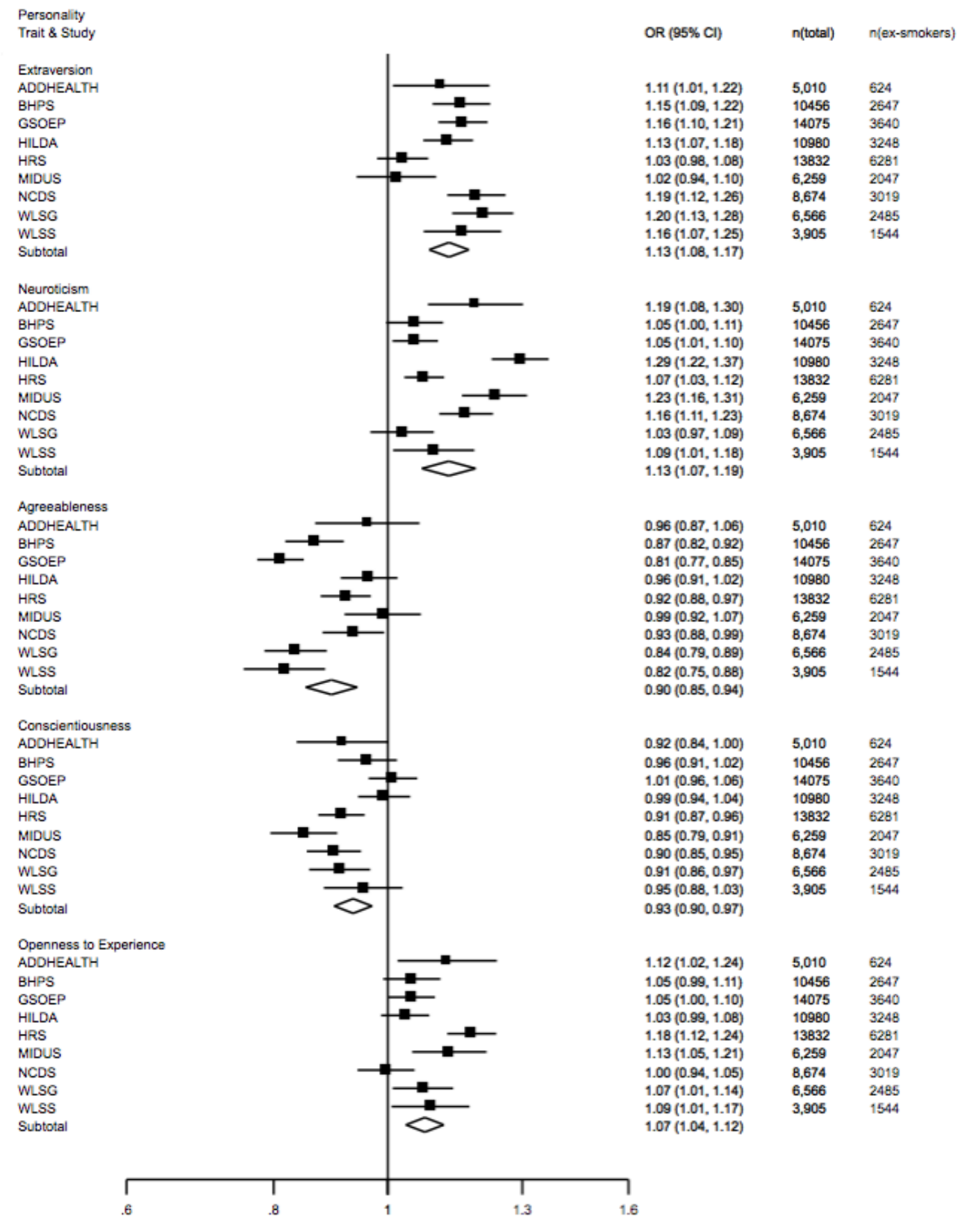

Supplemental Figure 2. Cross-sectional associations between the Five-Factor Model personality traits and being an ex-smoker at the baseline. Values are odds ratios per 1 standard deviation increment in personality trait. Add Health, National Longitudinal Study of Adolescent Health; BHPS, British Household Panel Survey; GSOEP, German SocioEconomic Panel Study; HILDA, Household, Income and Labour Dynamics in Australia; HRS, Health and Retirement Study; MIDUS, Midlife in the United States; NCDS, National 
Online supplement: Personality and smoking

Child Development Study; WLSG, Wisconsin Longitudinal Study Graduate Sample; WLSS, Wisconsin Longitudinal Study Sibling Sample. 


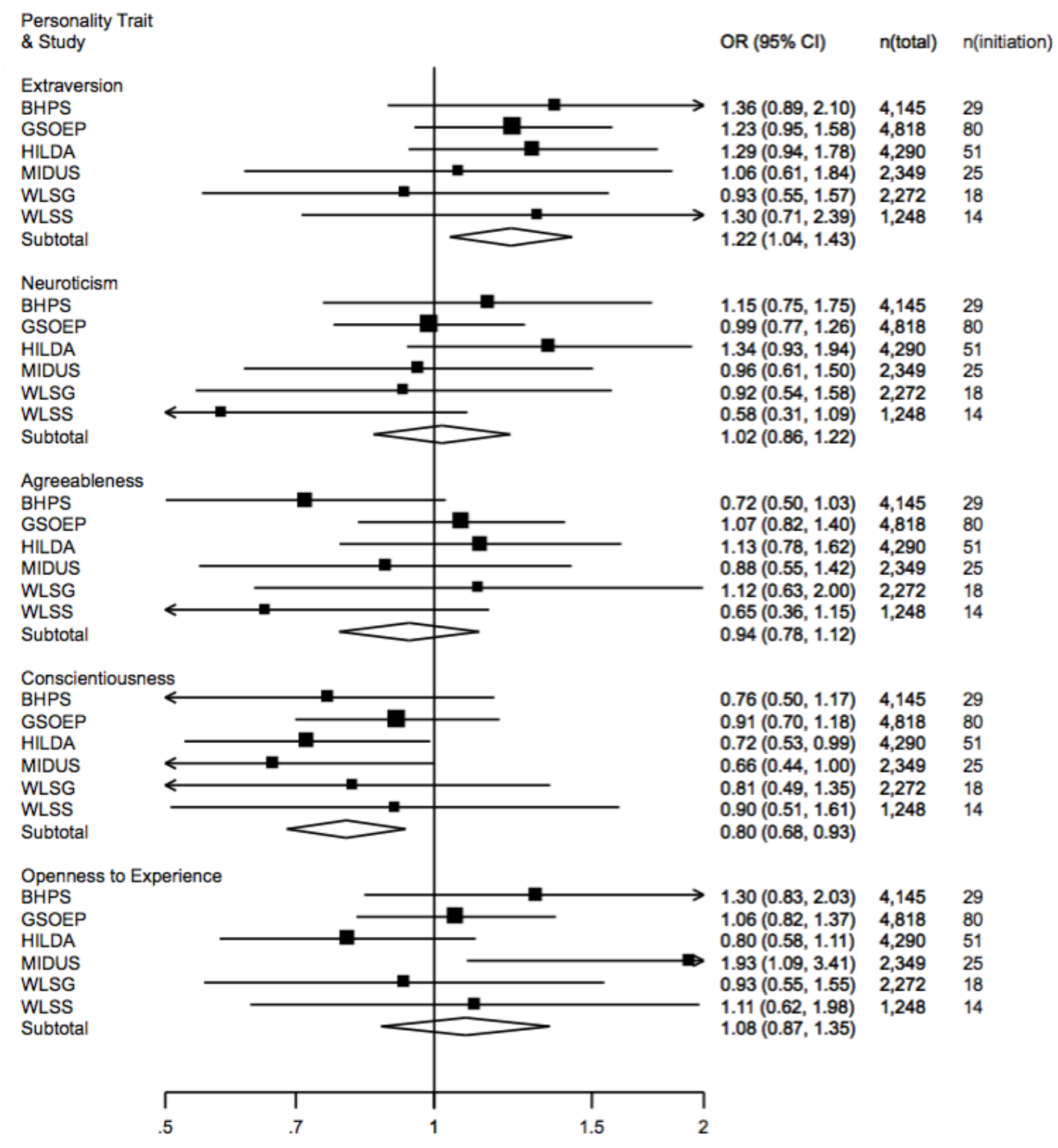

Supplemental Figure 3. Longitudinal associations between the Five-Factor Model personality traits and smoking initiation among non-smokers at the baseline. Values are odds ratios per 1 standard deviation increment in personality trait. BHPS, British Household Panel Survey; GSOEP, German Socio-Economic Panel Study; HILDA, Household, Income and Labour Dynamics in Australia; MIDUS, Midlife in the United States; WLSG, Wisconsin Longitudinal Study Graduate Sample; WLSS, Wisconsin Longitudinal Study Sibling Sample. 


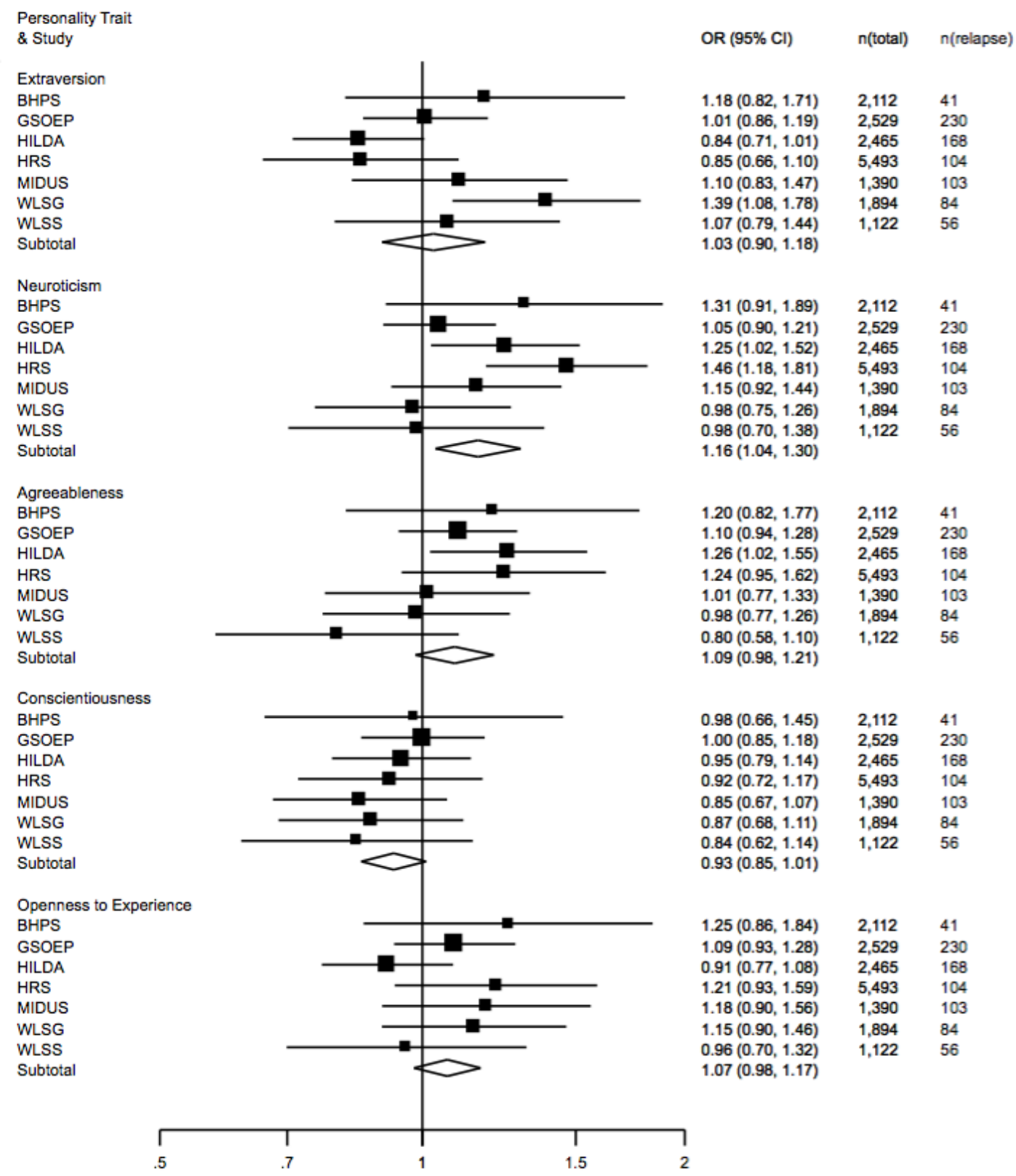

Supplemental Figure 4. Longitudinal associations between the Five-Factor Model personality traits and smoking relapse among never-smokers at the baseline. Values are odds ratios per 1 standard deviation increment in personality trait. BHPS, British Household Panel Survey; GSOEP, German Socio-Economic Panel Study; HILDA, Household, Income and Labour Dynamics in Australia; HRS, Health and Retirement Study; MIDUS, Midlife in the United States; WLSG, Wisconsin Longitudinal Study Graduate Sample; WLSS, Wisconsin Longitudinal Study Sibling Sample. 


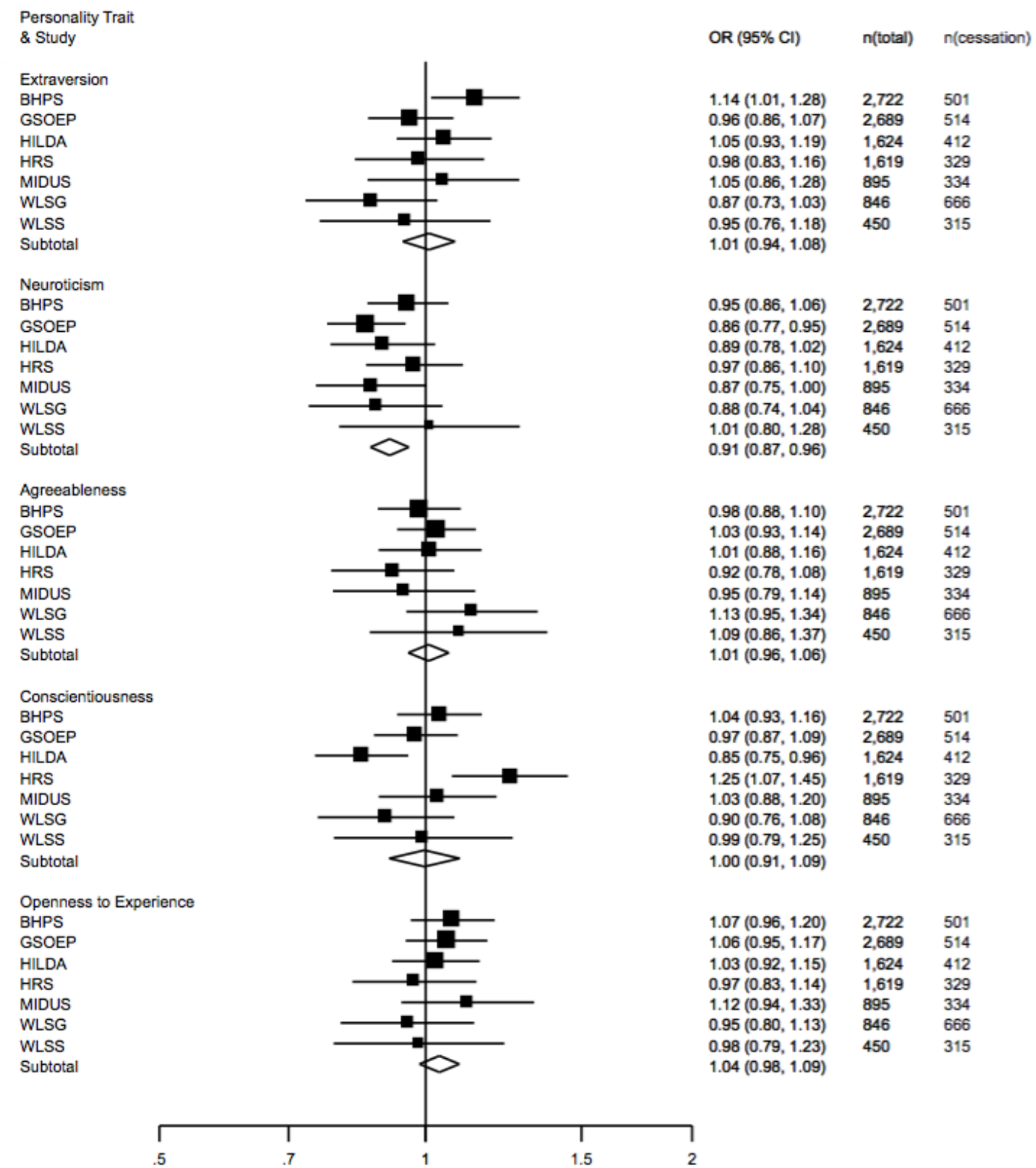

Supplemental Figure 5. Longitudinal associations between the Five-Factor Model personality traits and smoking cessation among smokers at the baseline. Values are odds ratios per 1 standard deviation increment in personality trait. BHPS, British Household Panel Survey; GSOEP, German Socio-Economic Panel Study; HILDA, Household, Income and Labour Dynamics in Australia; HRS, Health and Retirement Study; MIDUS, Midlife in the United States; WLSG, Wisconsin Longitudinal Study Graduate Sample; WLSS, Wisconsin Longitudinal Study Sibling Sample. 
References

1. Harris K.M. The National Longitudinal Study of Adolescent Health (Add Health), Waves I \& II, 1994-1996; Wave III, 2001-2002; Wave IV, 2007-2009 [machine-readable data file and documentation]. Chapel Hill, NC: Carolina Population Center, University of North Carolina at Chapel Hill.; 2009.

2. Donnellan M.B., Oswald F.L., Baird B.M., Lucas R.E. The mini-IPIP scales: tiny-yeteffective measures of the Big Five factors of personality. Psychol Assess 2006; 18: 192-203.

3. Taylor M.F., Brice J., Buck N., Prentice-Lane E. British Household Panel Survey-User Manual-Volume A: Introduction, Technical Report and Appendices. Colchester, England: University of Essex; 2010.

4. John O.P., Donahue E.M., Kentle R.L. The "Big Five" inventory - version 4a and $5 a$. University of California, Berkeley: Institute of Personality and Social Research.; 1991.

5. John O.P., Naumann L.P., Soto C.J. Paradigm shift to the integrative big-five trait taxonomy: History, measurement, and conceptual issues. In: John O.P., Robins R.W., Pervin L.A., editors. Handbook of Personality: Theory and Research. New York: Guilford Press; 2008. p. $114-58$.

6. Wagner G., Frick J., Schupp J. The German Socio-Economic Panel study (SOEP)evolution, scope and enhancements. J Appl Soc Sci Studies 2007; 127: 139-69.

7. Gerlitz J., Schupp J. Zur Erhebung der Big-Five-basierten Persönlichkeitsmerkmale im SOEP [The measurement of the Big Five personality traits in the SOEP]. Berlin: DIW Berlin; 2005. 
8. Wooden M., Watson N. The HILDA Survey and its Contribution to Economic and Social Research (So Far)*. Economic Record 2007; 83: 208-31.

9. Saucier G. Mini-markers: A brief version of Goldberg's unipolar Big-Five markers. J Pers Assess 1994; 63: 506-16.

10. Juster F.T., Suzman R. An overview of the Health and Retirement Study. J Hum Resour 1995: S7-S56.

11. Lachman M.E., Weaver S.L. The Midlife Development Inventory (MIDI) personality scales: Scale construction and scoring. Waltham, MA: Brandeis University 1997.

12. Brim O.G., Baltes P.B., Bumpass L.L., Cleary P.D., Featherman D.L., Hazzard W.R., et al. National Survey of Midlife Development in the United States (MIDUS), 1995-1996. 2011 DOI:10.3886/ICPSR02760.v8.

13. Power C., Elliott J. Cohort profile: 1958 British birth cohort (National Child Development Study). Int J Epidemiol 2006; 35: 34-41.

14. Goldberg L.R., Johnson J.A., Eber H.W., Hogan R., Ashton M.C., Cloninger C.R., et al. The international personality item pool and the future of public-domain personality measures. Journal of Research in Personality 2006; 40: 84-96.

15. Herd P., Carr D., Roan C. Cohort Profile: Wisconsin longitudinal study (WLS). Int J Epidemiol 2014; 43: 34-41. 